\title{
Adaptations to cursoriality and digit reduction in the forelimb of the African wild dog (Lycaon pictus)
}

\author{
Heather F Smith ${ }^{\text {Corresp., 1, 2, 3, } 4 \text {, Brent Adrian }}{ }^{1}$, Rahul Koshy ${ }^{3}$, Ryan Alwiel ${ }^{4}$, Aryeh Grossman ${ }^{1,4}$ \\ 1 Department of Anatomy, College of Graduate Studies, Midwestern University, Glendale, AZ, United States of America \\ 2 School of Human Evolution and Social Change, Arizona State University, Tempe, AZ, United States of America \\ 3 Arizona College of Osteopathic Medicine, Midwestern University, Glendale, AZ, United States of America \\ ${ }^{4}$ College of Veterinary Medicine, Midwestern University, Glendale, AZ, United States of America \\ Corresponding Author: Heather F Smith \\ Email address: Heather.F.Smith@asu.edu
}

Background. The African wild dog (Lycaon pictus), an endangered canid native to southern and eastern Africa, is distinct among canids in being described as entirely tetradactyl and in its nomadic lifestyle and use of exhaustive predation to capture its prey instead of speed, strength, or stealth. These behavioral and morphological traits suggest a potentially unique set of adaptations.

Methods. Here, we dissected the forelimbs of an adult male L. pictus specimen and performed detailed descriptions and quantitative analyses of the musculoskeletal anatomy.

Results. Statistical comparisons of muscle masses and volumes revealed that $L$. pictus has relatively smaller wrist rotators ( $\mathrm{mm}$. pronator teres, pronators quadratus, supinator) than any other included carnivoran taxon, suggesting adaptive pressures for antebrachial stability over rotatory movement in the carpus of $L$. pictus. While a complete digit I is absent in L. pictus, a vestigial first metacarpal was discovered, resulting in changes to insertions of $\mathrm{mm}$. extensor digiti I et II, abductor (et opponens) digiti I, and flexor digiti I brevis. Mm. anconeus, brachialis, and flexor carpi ulnaris caput ulnare all have more extensive origins in L. pictus than other canids suggesting an emphasis on posture and elbow stability. M. triceps brachii caput laterale has a larger origin in L. pictus, and $\mathrm{m}$. triceps brachii caput longum has an additional accessory head. Electromyographic (EMG) studies have shown this muscle is active during the stance phase of trotting and galloping and is important for storing elastic energy during locomotion. We interpret these differences in size and attachments of muscles in L. pictus as adaptations for long distance running in this highly cursorial species, likely important for exhaustive predation. Absence of a full digit I in L pictus may increase speed and stride length; however, the retention of a vestigial digit permits the attachment of reduced pollical muscles which may provide additional stability and proprioception to the carpus. 


\title{
1 Adaptations to cursoriality and digit reduction in the 2 forelimb of the African wild dog (Lycaon pictus)
}

3

4

5

6

7

8

9

10

11

12

13

14

15

16

17

Heather F. Smith ${ }^{1,2,3,4^{*}}$, Brent Adrian ${ }^{1}$, Rahul Koshy ${ }^{2}$, Ryan Alwiel ${ }^{3}$, Aryeh Grossman ${ }^{1,3}$

${ }^{1}$ Department of Anatomy, College of Graduate Studies, Midwestern University, Glendale, AZ United States of America

${ }^{2}$ Arizona College of Osteopathic Medicine, Midwestern University, Glendale, AZ United States of America

${ }^{3}$ College of Veterinary Medicine, Midwestern University, Glendale, AZ United States of America

${ }^{4}$ School of Human Evolution and Social Change, Arizona State University, Tempe, AZ United States of America

Corresponding Author: Heather F. Smith, Ph.D., Department of Anatomy, Midwestern University, 19555 N. 59th Ave., Glendale, AZ 85308 E-mail: hsmith@midwestern.edu, Tel: 1-623-572-3726, Fax: 1-623-572-3679.

Key words: canidae, caniformia, Lycaon, myology, forelimb, functional morphology

\begin{abstract}
Background. The African wild dog (Lycaon pictus), an endangered canid native to southern and eastern Africa, is distinct among canids in being described as entirely tetradactyl and in its nomadic lifestyle and use of exhaustive predation to capture its prey instead of speed, strength, or stealth. These behavioral and morphological traits suggest a potentially unique set of adaptations.

Methods. Here, we dissected the forelimbs of an adult male L. pictus specimen and performed detailed descriptions and quantitative analyses of the musculoskeletal anatomy.

Results. Statistical comparisons of muscle masses and volumes revealed that $L$. pictus has relatively smaller wrist rotators (mm. pronator teres, pronators quadratus, supinator) than any other included carnivoran taxon, suggesting adaptive pressures for antebrachial stability over rotatory movement in the carpus of $L$. pictus. While a complete digit I is absent in $L$. pictus, a vestigial first metacarpal was discovered, resulting in changes to insertions of $\mathrm{mm}$. extensor digiti I et II, abductor (et opponens) digiti I, and flexor digiti I brevis. Mm. anconeus, brachialis, and flexor carpi ulnaris caput ulnare all have more extensive origins in L. pictus than other canids suggesting an emphasis on posture and elbow stability. M. triceps brachii caput laterale has a larger origin in $L$. pictus, and $\mathrm{m}$. triceps brachii caput longum has an additional accessory head. Electromyographic (EMG) studies have shown this muscle is active during the stance phase of trotting and galloping and is important for storing elastic energy during locomotion. We interpret these differences in size and attachments of muscles in $L$. pictus as adaptations for long distance running in this highly cursorial species, likely important for exhaustive predation. Absence of a full digit I in $L$ pictus may increase speed and stride length; however, the retention of a vestigial digit permits the attachment of reduced pollical muscles which may provide additional stability and proprioception to the carpus.
\end{abstract}

\section{Introduction}


46

47

48

49

50

51

52

53

54

55

56

57

58

59

60

61

62

63

64

65

66

67

68

69

70

71

72

73

74

75

76

77

78

79

80

81

82

83

84

85

86

87

88

89

90

91

92

The African wild dog (Lycaon pictus), also known as the African painted dog or Cape hunting dog, is unique among canids in many ways. Phylogenetically, it falls as the outgroup of the "wolf" clade of canids (Toh et al., 2005). However, unlike other canid species, L. pictus utilizes exhaustive predation instead of speed, strength, or stealth to hunt and capture its prey. Sophisticated hunting behaviors are deployed, and some packs exhibit quorums on decisions to hunt (Walker, 2017). They communicate their vote via "sneezing" or a sharp exhale through their nostrils (Walker, 2017). They feed primarily on antelope, which they hunt by running the prey to exhaustion. Larger prey are hunted in packs, while smaller prey such as rodents and hares are hunted by individual dogs (Woodroffe, 2007). L. pictus achieves higher successful hunt rates (greater than 60\%) than even lions (27-30\%) and hyenas (25-30\%), although they frequently lose their kills to these larger predators (Creel, 1998). It is a hypercarnivore, a dietary adaptation which results in specialized craniodental morphology compared to other canids. L. pictus also exhibits a nomadic lifestyle with packs traveling up to $50 \mathrm{~km}$ per day (Woodroffe, 2004) and geographically extensive home ranges of between 560 to $3000 \mathrm{~km}^{2}$ (Castello, 2018). These unique hunting and behavioral characteristics suggest that the anatomy of L. pictus should be adapted for long-distance, endurance running. In particular, their forelimb anatomy likely exhibits adaptations to compensate for this type of lifestyle. However, this hypothesis has not been tested.

An additional morphological trait distinguishing L. pictus from other caniforms is its reported absence of a manual digit I (pollex) or "dewclaw". The absence of digit I may allow for increased speed and stride length in L. pictus, thus facilitating long-distance pursuit of prey (Van Valkenburgh, 1987; Creel and Creel, 2002). Across mammals, there is a trend among cursorial predators towards digit loss and limb elongation, both of which enable speed and enhance prey capture capabilities (Van Valkenburgh, 1987). Although the fossil record of Lycaon is poorly known, limited material suggests that Lycaon, Canis, and Cuon may have diverged from a common ancestor in the Pliocene (Kurtén, 1968; Wayne, 1993, Stiner et al., 2001). The subsequent reduction of the first digit in the Lycaon lineage evolved shortly thereafter, alongside dental adaptations for hypercarnivory (Martinez-Navarro et al., 2003; Hartstone-Rose, 2010). A recent study on L. pictus genomics identified several genes associated with digit I loss (Chavez et al., 2019). Digit reduction in L. pictus develops through apoptosis of the first digit during embryonic development, specifically via a pathway that generally regulates apoptosis of interdigital tissue $=$ (Chavez et al., 2019). Nevertheless, it is currently unknown how the lack of digit I in L. pictus may affect the morphology and attachment points of the numerous muscles of the antebrachium and manus.

In addition to its unique anatomical and behavioral adaptations, L. pictus is also an important study subject due to its conservation status. It is classified as Endangered by the International Union for Conservation of Nature (IUCN) with as few as 1400 mature individuals present in the wild (Woodroffe \& Sillero-Zubiri, 2012). Much of the population inhabits savanna and arid zones in southern and southeastern Africa. The population size is declining, primarily due to human-caused habitat fragmentation (McNutt, 2008), and there is currently no detailed documentation of their anatomy. The descriptions, illustrations, and comparative quantitative analyses of their forelimb morphology provided here can serve as a useful reference for exotic animal veterinarians and other clinicians, as well as conservation scientists who work with these animals. 
93

94

95

96

97

98

99

100

101

102

103

104

105

106

107

108

109

110

111

112

113

114

115

116

117

118

119

120

121

122

123

124

125

126

127

128

129

130

131

132

133

134

135

136

137

\section{Materials \& Methods}

\section{Dissection and Muscle Descriptions}

This research was conducted on the left and right forelimbs of an adult male African wild dog $(L$. pictus). The captive specimen was donated to the Arizona Research Collection for Integrative Vertebrate Education and Study (ARCIVES) at Midwestern University by the Arizona Center for Nature Conservation/Phoenix Zoo. The specimen was received by ARCIVES post-necropsy, and consequently the limbs had been disconnected from the trunk and several extrinsic back muscles had been disconnected. Following necropsy, the forelimbs were preserved by submersion in a $10 \%$ formaldehyde solution. The body condition of the animal, despite being disarticulated, was assessed to be good and muscle tone was moderate.

Dissections took place in the Department of Anatomy, College of Veterinary Medicine at Midwestern University (Glendale, AZ). Photodocumentation for all structures was performed using a Nikon DSLR camera throughout the dissection process. Using a veterinary atlas and published descriptions as reference, exposed muscles and neurovasculature were compared to other caniforms for identification and comparison purposes. In particular, we utilized descriptive studies on the myology of the domestic dog, Canis familiaris, (Evans \& de Lahunta, 2013), pampas fox, Lycalopex gymnocercus (de Sousa et al., 2018) red panda, Ailurus fulgens (Fisher et al., 2008), and lesser grison, Galictis cuja (Ercoli et al., 2015) as primary comparative references. Each muscle was described in detail, including its gross morphology, fiber direction, number of bellies, attachment points, and relationships to other structures. As the dissection progressed, muscles were carefully detached from the forelimb bones to identify specific osteological attachment sites. We mapped the origins and insertions of muscles by drawing onto transparent sheet protectors over printed photographs of comparative bones. These maps were then converted into digital illustrations to clarify muscle descriptions. We also collected quantitative muscle data: Mass was recorded with an Accuteck ${ }^{\circledR}$ electronic balance, and lengths and widths were assessed using Mitutoyo digital calipers. Ultimately, morphology was compared to that of other published carnivoran species to identify adaptations for cursoriality, longdistance endurance running, and digit reduction in L. pictus.

\section{Quantitative analyses}

To assess how forelimb muscular proportions of L. pictus compare to those of other carnivorans, we conducted quantitative statistical analyses of muscle data, primarily following the approach of Taverne et al. (2018). First, the mass of each muscle (Table 1) was used to calculate the volume using the known muscle density value of $1.06 \mathrm{~g} \mathrm{~cm}^{-3}$ (Mendez \& Keys, 1960). Volumes were then $\log _{10}$ transformed to normalize the data and regressed against the combined weight of the forelimb muscles as this accounts for differences in overall body size in comparisons to other carnivoran taxa.

We combined muscles into functional groups as defined by Taverne et al. (2018): elbow extensors, elbow flexors, wrist extensors, wrist flexors, and wrist rotators. The additional categories of humeral and scapular muscle groups in Taverne et al. (2018) could not be applied to the current dataset due to the damage of certain key muscles (e.g., mm. trapezius, rhomboideus, latissimus dorsi) in our L. pictus specimen during necropsy. We compiled comparative data on forelimb muscle volume proportions for 17 felid and canid species from 
138 Taverne et al. (2018) and compared those to L. pictus. We conducted a Principal Component 139 Analysis using the aforementioned volume proportions for the forelimb muscle groups using 140 SPSS 25 (IBM Corp.).

141 We also compiled comparative data on individual muscle masses from published literature, 142 including Cuon alpinus and Vulpes vulpes (Taverne et al., 2018), Galictis cuja (Ercoli et al., 143 2015), Lynx lynx (Viranta et al., 2016), and Leopardus pardalis (Julik et al., 2012). Relative 144 proportions of muscles were calculated as described above and compared graphically and via 145 Principal Component Analysis in SPSS 25 (IBM Corp.). This step permits the evaluation of 146 separate muscles within each functional group, as well as the inclusion of additional scapular 147 muscles not included in the functional group analyses.

148 While it has been documented that specimens preserved in formalin may experience shrinkage 149 (e.g., Fox et al., 1985), this phenomenon is unlikely to have a significant impact on the analyses

150

151

152

153

154

155

156

157

158

159

160

161

162

163

164

165

166

167

168

169

170

171

172

173

174

175

176

177

178

179

180

181

182

conducted here for several reasons. First, as the data compared here are percentages, it is likely that all muscles are impacted equally, and thus the ratios should be accurate. Second, in the comparative sample, the muscle data of Taverne and colleagues also used formalin-fixed specimens, so the values are directly comparable.

\section{Results}

\section{Vestigial digit 1}

While the majority of the bony anatomy of L. pictus generally coincides with standard canid osteological patterns, there is one notable exception. During reflection of the fascia around the medial carpus, a small bony protrusion emerged. Extensive cleaning revealed an unexpected vestigial metacarpal I (Fig. S1). The bone is slender, tapering in the center and rounded on both ends, resembling an elongated dumbbell. It is $19.8 \mathrm{~mm}$ long, making it approximately $30 \%$ the length of metacarpal II (65 mm long). It measures $4.5 \mathrm{~mm}$ wide at the base, $2.9 \mathrm{~mm}$ wide at the midshaft, and 4.7 wide at its head. No accompanying sesamoid bone was observed, and there were no associated phalanges. The metacarpal I serves as a muscle attachment site for several typical carnivoran pollical muscles, discussed in further detail below.

\section{Quantitative analyses}

In the Principal Component Analysis, the first three PCs explain greater than $90 \%$ of the variance: PC1 51.3\%, PC2 30.0\%, and PC3 10.9\%. Terrestrial and arboreal species separated along PC1 axis. The elbow extensor group loaded most negatively along this axis (-0.989), while wrist rotator group loaded most positively $(0.854)$. Since these muscle groups generated the greatest degree of separation among locomotor groups, we performed a follow-up Ordinary Least Squares regression analysis regressing wrist rotator values over elbow extensor values. The resulting plot illustrates an almost-perfect separation between arboreal and terrestrial taxa (Fig 1, Table 2). Additionally, larger-bodied terrestrial species that spend more time running cluster together, separate from the smaller-bodied short-distance scampering taxa (Fig 1). L. pictus clusters with the runners, along with Vulpes vulpes (red fox), Cuon alpinus (dhole), Acinonyx jubatus (cheetah), and Hyaena hyaena (striped hyena). In particular, these species are characterized by relatively smaller proportions of wrist rotators and relatively larger elbow extensors. Of all included taxa, L. pictus has the smallest wrist rotator group.

Peer] reviewing PDF | (2020:06:49981:1:1:NEW 29 Jul 2020) 
183 Of the taxa for which individual muscle mass data were available, L. pictus was found to possess 184 smaller proportions of $\mathrm{mm}$. pronator teres, pronator quadratus, supinator, abductor digiti I 185 longus, extensor digiti I et II than any other included taxon (Table 3). L. pictus has the highest values in the sample of $\mathrm{m}$. acromiodeltoideus (also high $\mathrm{m}$. spinodeltoideus) and $\mathrm{m}$. infraspinatus. The teres minor of L. pictus is also relatively large, a trait shared with L. pardalis. Compared to the felids in the sample, all three canids shared larger $\mathrm{mm}$. articularis humeri and triceps brachii, and smaller mm. teres major, biceps brachii, abductor digiti I longus, supinator, pronator teres, and pronator quadratus.

Compared to the other canids in the sample, Cuon alpinus and Vulpes vulpes, L. pictus has dramatically proportionally larger mm. deltoideus, infraspinatus, brachialis, flexor carpi ulnaris caput humerale, and flexor carpi radialis. It has relatively smaller mm. triceps brachii (all heads combined), anconeus, extensor digitorum communis, abductor digiti I longus, supinator, pronator teres, pronator quadratus, flexor digitorum superficialis, and flexor carpi ulnaris caput ulnare. The two larger-bodied canids ( $>15 \mathrm{~kg})$, C. alpinus and L. pictus, share larger mm. supraspinatus, extensor carpi ulnaris, extensor digitorum lateralis, and smaller m. extensor digiti I et II.

198

199

200

201

202

203

204

205

206

207

208

209

210

211

212

213

214

215

216

217

218

219

220

221

222

223

224

225

226

227

\section{Muscle Descriptions Extrinsic muscles of the shoulder}

M. trapezius: This muscle was extensively damaged during necropsy, so its origin and the morphology of its proximal fibers could not be evaluated. Its distal fibers consist of a thin muscle belly with muscle fibers coursing inferolaterally towards the spine of the scapula (Fig. 2). The muscle lies superficial to the supraspinatus (Fig. 2). Near its insertion, it courses adjacent to the $\mathrm{m}$. omotransversarius, and their bellies adhere to each other by a thin band of fascia. It inserts onto the proximal two-thirds of the cranial aspect of the scapular spine via fleshy fibers (Figs. 2 , 3A). A separable pars thoracica and pars cervicalis could not be identified in this specimen, likely due to damage during necropsy. M. trapezius acts to move the scapula cranially and dorsally, thus elevating the forelimb, as well as stabilize the scapula.

M. latissimus dorsi: The origin of this muscle was damaged during necropsy. It is a thick sheet of muscle, slightly thicker than m. teres major (Fig. 4). Remaining muscle fibers run perpendicular to the length of the humerus (Fig. 4). There is an aponeurosis between the $\mathrm{m}$. latissimus dorsi and $\mathrm{m}$. teres major, and the muscles fuse distally to insert on the teres major tuberosity of the humerus via a thick conjoined tendon (Figs. 3A, 5). M. latissimus dorsi acts to retract and abduct the forelimb. When the forelimb is fixed, it moves the trunk cranially.

M. omotransversarius: The origin of this muscle was damaged during necropsy. It is a thin muscle belly similar in appearance to the m. trapezius but narrower (Fig. 2). Muscle fibers course caudolaterally, perpendicular to the spine of the scapula (Fig. 2). The muscle lies superficial to the craniodistal edge of $\mathrm{m}$. supraspinatus and is proximal to the origin of $\mathrm{m}$. deltoideus pars acromialis (Fig. 2). It inserts onto the distal $1 / 3$ of the scapular spine adjacent to the insertion of $\mathrm{m}$. trapezius, and onto the proximal acromion just proximal to the insertion of $\mathrm{m}$. deltoideus pars acromialis (Figs. 2, 3A). M. omotransversarius pulls the scapula cranially, advancing the forelimb. When the forelimb is fixed, it flexes the neck.

Peer] reviewing PDF | (2020:06:49981:1:1:NEW 29 Jul 2020) 
228

229

230

231

232

233

234

235

236

237

238

239

240

241

242

243

244

245

246

247

248

249

250

251

252

253

254

255

256

257

258

259

260

261

262

263

264

265

266

267

268

269

M. cleidobrachialis: The origin of this muscle was damaged during necropsy. It consists of a long round muscle belly on the cranial portion of the brachium which tapers towards its insertion (Figs. 2, 4). Muscle fibers run parallel to the long axis of the muscle (Figs. 1, 3). The muscle travels cranial to the $\mathrm{m}$. deltoideus pars acromialis and lateral to the $\mathrm{m}$. pectoralis superficialis (Figs. 2, 4). M. cleidobrachialis inserts onto a small area of the craniodistal humerus between the $\mathrm{m}$. biceps brachii and $\mathrm{m}$. brachialis muscle bellies (Figs. 2, 4, 5A). M. cleidobrachialis draws the forelimb cranially, or flexes the neck if the forelimb is fixed.

M. pectoralis superficialis: This muscle was extensively damaged during necropsy; however, its attachment to the humerus was preserved. Muscle fibers are positioned medial to the $\mathrm{m}$. cleidobrachialis and lateral to the m. biceps brachii (Figs. 2, 4). Muscle fibers course perpendicular to the long axis of the humerus (Figs. 2, 4). It inserts along the proximal $2 / 3$ of the cranial surface of the humerus (Figs. 2, 4, 5A-B). M. pectoralis superficialis adducts the forelimb and may draw the forelimb cranially or caudally depending on the portion of the muscle that is active and the position of the limb.

\section{M. deltoideus:}

Pars scapularis: This muscle originates from the scapular spine indirectly via a connection to the aponeurosis of $\mathrm{m}$. infraspinatus (Fig. 2). It is a flat fusiform muscle which lies superficial to the inferior portion of the infraspinatus and completely overlies the $\mathrm{m}$. teres minor (Fig. 1). The muscle fibers run parallel to the length of the spine of the scapula (Fig. 2). It inserts onto the $\mathrm{m}$. deltoideus pars acromialis and has no direct connection to the humerus (Fig. 2).

Pars acromialis: The origin of this muscle is from the acromion process of the scapula distal to the insertion of m. omotransversarius (Figs. 2, 3A). Its muscle belly is fusiform and has a prominent aponeurosis covering it proximally (Fig. 2). The proximal muscle fibers course parallel to the scapular spine, and then slowly curve distally to become parallel to the humerus (Fig. 2). It has a large insertion onto the deltoid tuberosity on the lateral humerus (Figs. 2, 5B). M. deltoideus flexes the glenohumeral joint and abducts the humerus.

M. supraspinatus: This muscle has a large, thick muscle belly originating from and fully filling the supraspinous fossa to the tip of the spine of the scapula (Figs. 2, 3A). The muscle is elliptical in shape, similar to- but wider than the $\mathrm{m}$. infraspinatus. Muscle fibers run obliquely from the spine of the scapula to the distal margins of the muscle belly. An aponeurosis covers the proximal $1 / 3$ of the muscle surface. There is a thick tendon in the middle of the muscle which travels $2 / 3$ proximally up the muscle from the glenohumeral joint to the proximal point and dissipates, similar to the pattern in $\mathrm{m}$. infraspinatus. It inserts onto the greater tubercle of the humerus along its cranial aspect, proximal to the insertion of $\mathrm{m}$. infraspinatus (Figs. 2, 3, 5B). As with the other muscles of the rotator cuff, $\mathrm{m}$. supraspinatus stabilizes the shoulder. It also extends the glenohumeral joint, resulting in advancement of the forelimb.

Peer] reviewing PDF | (2020:06:49981:1:1:NEW 29 Jul 2020) 
270

271

272

273

274

275

276

277

278

279

280

281

282

283

284

285

286

287

288

289

290

291

292

293

294

295

296

297

298

299

300

301

302

303

304

305

306

307

308

309

310

311

312

313

314

315

M. infraspinatus: This muscle originates from and occupies the infraspinous fossa (Fig. 3A). It has a thick muscle belly with an elliptical shape that tapers on its proximal and distal ends. Distal portions of the muscle are deep to the $\mathrm{m}$. deltoideus pars scapularis. The muscle has various muscle fiber directions with the cranial and caudal fibers coursing diagonally to converge on the midline of the muscle. The tendon adhering to the humerus is located within the muscle belly and travels $3 / 4$ of the length of the $\mathrm{m}$. infraspinatus before widening and inserting on the greater tubercle of the humerus (Fig. 5B). The flat portion of the tendon parallels the spine of the scapula. The infraspinatus has an extensive aponeurosis on its cranial portion covering about one-third of the superficial muscle. It inserts onto the greater tubercle of the humerus inferior to the insertion of $\mathrm{m}$. supraspinatus (Fig. 5B). M. infraspinatus acts to laterally rotate the humerus and stabilize the glenohumeral joint. It can also contribute to flexion or extension of the shoulder, depending on the position of the humeral head relative to the glenoid when the muscle contracts.

M. teres minor: $M$. teres minor originates from the distal three quarters of the infraspinous fossa margin (Fig. 2, 3A). Proximally, the muscle is thin and wide, and then it thickens quickly to a spindle shape and tapers distally (Figs. 2, 5B). Its insertion is the teres minor tuberosity on the lateral proximal aspect of the greater tubercle of the humerus (Figs. 2, 5B). M. teres minor flexes the glenohumeral joint.

M. teres major: The origin of this muscle was damaged during necropsy. The muscle forms a thick sheet which courses adjacent to $\mathrm{m}$. latissimus dorsi and adheres to it near the origin of the $\mathrm{m}$. tensor fascia antebrachii on $\mathrm{m}$. latissimus dorsi (Fig. 3). It inserts broadly onto the teres major tuberosity (Figs. 3, 5A) cranial to the insertion of $\mathrm{m}$. triceps brachii caput mediale. The attachment of $\mathrm{m}$. teres major onto the humerus is thicker and stronger than the attachments of the rotator cuff muscles. M. teres major flexes the glenohumeral joint, drawing the humerus caudally. It may also medially rotate the humerus, resisting lateral rotation.

M. subscapularis: This is a large, thick muscle which originates from the distal $2 / 3$ of the subscapular fossa (Fig. 3B) distal to the presumed insertion of m. serratus ventralis. Its broad fibers are divided into four pennate portions which occupy much of the subscapular fossa. The two cranialmost pennations are broad and triangular, while the two caudalmost pennations are elongated and course parallel to the caudal border of the scapula. Its tendon contributes to the glenohumeral joint capsule and inserts onto the tip of the lesser tubercle (Fig. 5A). M. subscapularis adducts and extends the glenohumeral joint. It also stabilizes the glenohumeral joint by medially rotating the humerus in order to prevent undesired lateral rotation.

\section{Intrinsic muscles of the arm}

\section{Cranial brachium}

M. biceps brachii: M. biceps brachii has a single, spindle-shaped belly that originates from the supraglenoid tubercle of the scapula (Figs. 3A, 4). Its thick tendon crosses over the head of the humerus through the intertubercular groove of the humerus (Fig. 4), and it courses the length of the muscle. An aponeurosis covers the muscle superficially and also the proximal, deep twothirds of the muscle (Figs. 2, 4, 6, 7, 8). The muscle belly lies on the medial side of the humerus with fiber orientation parallel to the humerus (Figs. 4, 7). The tendon of the m. biceps brachii

Peer] reviewing PDF | (2020:06:49981:1:1:NEW 29 Jul 2020) 
316

317

318

319

320

321

322

323

324

325

326

327

328

329

330

331

332

333

334

335

336

337

338

339

340

341

342

343

344

345

346

347

348

349

350

351

352

353

354

355

356

357

358

combines with the $\mathrm{m}$. brachialis tendon before bifurcating and inserting on the radial and ulnar tuberosities (Figs. 9B, 10A). M. biceps brachii flexes the elbow and extends the glenohumeral joint. It also acts to stabilize the glenohumeral joint when the forelimb is fixed.

M. tensor fasciae antebrachii: This is a thin, flat, wide muscle that arises via a thin aponeurosis on the surface of $\mathrm{m}$. latissimus dorsi (Fig. 4). The muscle belly tapers distally and inserts onto the medial ulna and the antebrachial fascia (Figs 4, 9B). This muscle tenses the antebrachial fascia and assists $\mathrm{m}$. triceps brachii in extending the elbow.

M. articularis humeri (coracobrachialis): This is a thin, delicate fusiform slip of muscle whose origin cannot be determined definitively due to necropsy damage (Fig. 4). The muscle belly lies over the lesser tubercle of the humerus, and is medial to the $\mathrm{m}$. teres major insertion, $\mathrm{m}$. triceps brachii medial head origin, and belly of $\mathrm{m}$. brachioradialis (Fig. 4). It inserts onto the craniomedial aspect of the proximal humerus (Fig. 5A). M. articularis humeri stabilizes the glenohumeral joint.

M. brachialis: The origin site of this muscle begins at a caudolateral divot on the proximal greater tubercle of the humerus (Fig. 5B). Its two lines of origin diverge distally from this divot. One origin follows the lateral side of the tricipital line along the deltoid tuberosity in the proximal half of the humerus and courses medially and distally to the cranial side, half-way down the humerus (Fig. 5B). The other line of origin is straight on the caudal aspect of the proximal two-thirds of the humerus, ending at the origin of the anconeus (Fig. 5A-B). The fibers of the muscle belly are minimally apparent, giving the belly a flat appearance (Figs. 2, 4, 6, 7). It occupies the entire lateral brachium and passes craniomedially in its distal half (Figs. 4, 6, 7).

The muscle becomes tendinous and fuses with the tendon of $\mathrm{m}$. biceps brachii before bifurcating and inserting onto the radial and ulnar tuberosities (Figs. 9B, 10A). M. brachialis flexes the elbow joint.

\section{Caudal brachium}

\section{M. triceps brachii:}

Caput magnum: It should be noted that this head is not listed in the Nomina Anatomica Veterinaria, because it was previously undescribed. We define the $\mathrm{m}$. triceps brachii caput magum here as a large head of $\mathrm{m}$. triceps brachii that is positioned caudally and laterally in the $\mathrm{m}$. triceps brachii complex. It originates from the caudal two-thirds of the scapular margin and neck, medial to the origin of m. teres minor (Fig. 3B). The muscle belly has a tear-drop appearance, with the tip oriented distally towards the insertion (Fig. 2). It fuses via a strong tendon with the caput longum along the distal half of the lateral aspect of the humerus (Figs. 2, 4).

Caput longum: This head of $\mathrm{m}$. triceps brachii originates from the inferior border of the scapula lateral to the origin of the m. triceps brachii caput magnum (Fig. 3B). It has an elongated spindle-shaped appearance that tapers as it travels distally towards its insertion. It fuses with the caput magnum distally (Figs. 2, 4).

Peer] reviewing PDF | (2020:06:49981:1:1:NEW 29 Jul 2020) 
359

360

361

362

363

364

365

366

367

368

369

370

371

372

373

374

375

376

377

378

379

380

381

382

383

384

385

386

387

388

389

390

391

392

393

394

395

396

397

398

399

400
Caput mediale: This head of $\mathrm{m}$. triceps brachii originates from the intertubercular groove cranial to the insertion of $\mathrm{m}$. teres major (Fig. 5A). The muscle is long and spindle-shaped, narrow near its origin and thicker distally (Fig. 4).

Caput laterale: The lateral head of $m$. triceps brachii has a thick parallelogram shape (Fig. 2). It originates via a thin, tendinous band from the proximolateral third of the humeral shaft (Figs. 2, 9A). The muscle belly decreases in width but increases in thickness toward its insertion (Figs. 2, 9A).

Caput accessorium: The accessory head of $\mathrm{m}$. triceps brachii is long and thin with a broad origin from the lateral aspect of the humeral neck (Fig. 2, 5B). The attachment resembles an inverted tick mark (Fig. 5B). The muscle is situated between the caput mediale and caput magnum of the m. triceps brachii (Fig. 2). Most of the muscle is on the caudal aspect of the humerus and it slightly covers $\mathrm{m}$. articularis humeri and $\mathrm{m}$. brachialis proximally and $\mathrm{m}$. anconeus distally (Fig. 2).

The heads of $\mathrm{m}$. triceps brachii fuse distally and share a stout tendon of insertion onto the entirety of the proximal portion of the olecranon process, and part of the olecranon tuber on the lateral side of the ulna (Fig. 9A-B). General contributions to this large insertion site include: a strong round tendon formed by the caput accessorium that enters the olecranon groove, the caput laterale insertion on the lateral side of the olecranon, and a crescent-shaped caput magnus+longum tendon that covers the tendon of the caput accessorium (Fig. 9A-B). Together, the $\mathrm{m}$. triceps brachii are powerful extensors of the elbow and stabilize the joint during standing.

M. anconeus: The muscle belly of $\mathrm{m}$. anconeus is triangular and generally thin (Figs. 2, 4, 6). Its origin is V-shaped on the caudal aspect of the distal humerus and lies between the midpoint of the caudal shaft to the medial and lateral supracondylar crests (Fig. 5A-B). On the lateral supracondylar crest, it is adjacent to the $\mathrm{m}$. extensor carpi radialis and $\mathrm{m}$. brachialis (Fig. 5B). There is a large fat deposit in the olecranon fossa deep to the muscle at the caudal humerus. M. anconeus has a broad, fleshy insertion from the lateral side of the olecranon to the lateral aspect of the coronoid process (Fig. 5A-B). M. anconeus may assist the m. triceps brachii with extension of the elbow. However, it is likely that its more important role maybe in resisting elbow flexion during standing and maintaining stability at the joint.

\section{Muscles of the forearm Caudal antebrachium}

M. brachioradialis: This muscle has a long, thin, flat belly overlying $\mathrm{mm}$. extensor carpi radialis longus and brevis (Fig. 6,8). It originates from approximately the lateral aspect of the distal quarter of the humerus (Figs. 5B, 6). The muscle belly is covered with an extensive fascia, and crosses from lateral to medial, distal to m. extensor carpi radialis (Fig. 6). It inserts onto the distal quarter of radius (Fig. 10B). M. brachioradialis flexes the elbow joint. It may also weakly

Peer] reviewing PDF | (2020:06:49981:1:1:NEW 29 Jul 2020) 
401 supinate the antebrachium, but the tight attachment between the radius and ulna limits such

402 rotatory movements.

403

404

405

406

407

408

409

410

411

412

413

414

415

416

417

418

419

420

421

422

423

424

425

426

427

428

429

430

431

432

433

434

435

436

437

438

439

440

441

442

443

M. extensor carpi radialis: This muscle is generally spindle-shaped and has a fanning origin from lateral supracondylar ridge of the humerus (Figs. 5B, 6). An aponeurosis covers the proximal half of the caudal portion of the muscle (Fig. 6, 8). It has two distinct bellies which are fused at the origin and separate in its distal half (Fig. 6). Each belly gives rise to a tendon in the distal third of the radius and insert as described below (Fig. 6).

M. extensor carpi radialis longus: The portion comprising $\mathrm{m}$. extensor carpi radialis longus is approximately a third the size of m. extensor carpi radialis brevis (Fig. 6, 8). Its muscle fibers are parallel with the radius, and it is superficial to the $\mathrm{m}$. extensor carpi radialis brevis (Fig. 6). M. extensor carpi radialis longus has a smaller tendon than $\mathrm{m}$. extensor carpi radialis brevis, which inserts onto the base of metacarpal II (Fig. 11).

M. extensor carpi radialis brevis: M. extensor carpi radialis brevis is approximately three times larger than its counterpart (Fig. 6). Its belly originates in a fan-like arrangement and gives rise to a tendon that is significantly larger than the tendon for $\mathrm{m}$. extensor carpi radialis longus (Fig. 6). M. extensor carpi radialis brevis lies deep to the belly of m. extensor carpi radialis longus and has a tendinous insertion onto the base of metacarpal III (Fig. 11).

Both mm. extensor carpi radialis muscles primarily extend the carpal joint and may weakly flex the elbow.

M. extensor digitorum communis: This muscle originates from the proximal portion of the lateral epicondyle of the humerus (Figs. 5B,6). A thick band of fascia covers the edges of the muscle belly proximally and also connects to $\mathrm{m}$. extensor digitorum lateralis near its insertion (Fig. 6). The muscle belly is triangular and has an aponeurosis on its cranial aspect which lies deep to the m. extensor carpi radialis (Fig. 6). Its fibers converge in the middle of the muscle, and give rise to a tendon in the distal half of the radius (Fig. 6). The tendon of the m. extensor digitorum communis is approximately $50 \%$ thicker than that of $\mathrm{m}$. extensor digitorum lateralis (Fig. 6). The muscle remains undivided until reaching the wrist, where it divides into four tendons serving digits II-V. A dorsal sesamoid bone is embedded in each tendon as it crosses the metacarpophalangeal joint. Each sesamoid is a small, flat, elliptical bone and those of digits III and IV are largest. The tendons each insert on the extensor expansion at the distal phalanx of digits II-V (Fig. 11). The tendons of m. extensor digitorum communis attaching to metacarpal IV and $\mathrm{V}$ are fused with the tendons of $\mathrm{m}$. extensor digitorum lateralis. M. extensor digitorum communis extends the carpal joint, metacarpophalangeal, and interphalangeal joints of digits II$\mathrm{V}$.

M. extensor digitorum lateralis: This muscle is fusiform and its fibers originate from the lateral epicondyle of the humerus and lateral collateral ligament (Figs. 5B, 6). Its muscle belly gives rise to a tendon in the distal half of the radius along its caudal edge (Fig. 6). The muscle is covered by an aponeurosis on its cranial and caudal edges, and it lies between $\mathrm{m}$. extensor digitorum communis and $\mathrm{m}$. extensor carpi ulnaris, superficial to m. extensor digiti I et II (Fig. 6). The tendons of $\mathrm{m}$. extensor digitorum lateralis travel deep to $\mathrm{m}$. extensor digitorum communis over

Peer] reviewing PDF | (2020:06:49981:1:1:NEW 29 Jul 2020) 
444 metacarpal III and IV. The tendons insert on the extensor expansion at the distal phalanx of their 445 respective digits IV-V (Fig. 11). As they do so the two tendons fuse with $\mathrm{m}$. extensor digitorum 446 communis on the distal aspect of the proximal phalanges of digits IV and V (Fig. 11). M.

447 extensor digitorum lateralis does not serve digit III in either limb, which differ from the domestic $448 \operatorname{dog}$ (Evans \& de Lahunta, 2013). This muscle extends the carpal joint, metacarpophalangeal, and 449 interphalangeal joints of digits IV-V.

450

451

452

453

454

455

456

457

458

459

460

461

462

463

464

465

466

467

468

469

470

471

472

473

474

475

476

477

478

479

480

481

482

483

484

485

486
M. extensor digiti I et II (m. extensor pollicis longus et indicis proprius): This muscle has an elongated, thin belly on the lateral side of the antebrachium located between the ulna and radius. It originates from the middle third of the ulna on its craniolateral aspect. The muscle lies deep to $\mathrm{m}$. digitorum lateralis and travels through the concavity between the radius and ulna superficial to the interosseous membrane (Fig. 7). M. extensor digiti I et II lies immediately lateral to $\mathrm{m}$. abductor digiti I longus, and its fibers travel approximately parallel to the ulna. It becomes tendinous in the distal third of the ulna (Fig. 7). Its tendon is thin and crosses medially over the dorsal aspect of the manus beginning at the wrist. The tendon bifurcates on the proximal dorsal surface of metacarpal III. One branch travels medially along metacarpal II, and at its middle, the tendon courses deep to the tendon of $\mathrm{m}$. extensor digitorum communis, before it fuses on the lateral side of $\mathrm{m}$. extensor digitorum communis, on the proximal phalanx of digit II. The other belly travels further medially and also inserts on metacarpal II (Fig. 11). There is no insertion onto the vestigial digit I. M. extensor digiti I et II therefore acts to weakly extend the carpal joint, metacarpophalangeal, and interphalangeal joints of digit II, but does not act on vestigial digit I.

M. extensor carpi ulnaris: This is a spindle-shaped muscle originating from the lateral epicondyle of the humerus (Figs. 5B, 6,7). Muscle fibers are oriented caudally near the origin but become distally parallel with the ulna in its distal half (Figs. 6, 7). The tendon arises superficially in the proximal third of the ulna but appears distally from the deep aspect in the distal quarter of the ulna (Fig. 6). The belly is covered by an aponeurosis that is thicker on its deep surface. The tendon of insertion is more robust and stiffer than those of the other antebrachial muscles. It inserts onto the lateral side of the pisiform and the base of metacarpal V (Figs. 6, 11). In the domestic dog, the insertion on the pisiform (accessory carpal) is described as having two fiber bundles that leave the pisiform to fuse with $\mathrm{m}$. extensor carpi ulnaris (Evans \& de LaHunta, 2013). We did not observe this pattern in L. pictus. M. extensor carpi ulnaris abducts the carpal joint and supports the carpus, especially when it is extended and weightbearing.

M. abductor digiti I longus: The muscle belly of $\mathrm{m}$. abductor digiti I longus is long and flat, filling the entire interosseous space between the radius and ulna (Fig. 7). The muscle originates from the caudolateral radius, craniolateral ulna, and interosseous membrane (Fig. 9A, 10). It lies deep to $\mathrm{m}$. extensor digiti I et II on the lateral side of the antebrachium in the concavity between the radius and ulna. Muscle fibers travel diagonally, oriented cranially across the forearm. A wide, flat tendon arises and tapers distally at the cranial-most aspect of the radius. The tendon crosses obliquely from lateral to medial over the tendon of $\mathrm{m}$. extensor carpi radialis toward the medial side of the manus. There is a sesamoid bone in its tendon as it becomes thinner just

Peer] reviewing PDF | (2020:06:49981:1:1:NEW 29 Jul 2020) 
487 before its insertion onto the medial base of vestigial metacarpal I (Fig. 7). M. abductor digiti I

488 longus primarily acts to abduct the manus. While it attaches to the vestigial metacarpal I, the

489 bone is tightly adhered to the carpus and is unlikely to experience any notable movement at the

490 MC1-carpal joint.

491

492

493

494

495

496

497

498

499

500

501

502

503

504

505

506

507

508

509

510

511

512

513

514

515

516

517

518

519

520

521

522

523

524

525

526

527

528

529

M. supinator: This deep muscle completely covers the proximal quarter of the cranial radius. It is thin, flat, and fan-shaped with a heavy aponeurosis across most of its superficial surface (Fig 7). The muscle originates from the lateral epicondyle of the humerus and lateral collateral ligament (Fig. 5B). Its fibers are oriented medially, oblique to the radius. The muscle insertion is "U"-shaped on the proximal quarter of the radius (Fig. 10B). The medial portion of the insertion extends approximately twice that of the lateral portion (Fig. 10B). Unlike the domestic dog, there is no sesamoid bone within the tendon, (Evans \& de LaHunta, 2013). M. supinator acts to stabilize the elbow and weakly supinates the antebrachium, but limited rotatory movement is possible due to a tightly connected radius and ulna.

\section{Cranial antebrachium}

M. pronator teres: The belly of $\mathrm{m}$. pronator teres is spindle-shaped proximally and flatter distally (Fig. 8). An aponeurosis covers its distal half, and the muscle slightly overlaps $\mathrm{m}$. supinator medially (Fig. 8). The muscle originates from the craniodistal aspect of the medial epicondyle (Figs. 5A, 8). Its fibers are obliquely oriented in a cranial direction, and it inserts onto the proximal third of the craniomedial radius, distal to the insertion of m. supinator (Fig. 10B). As its name implies, $\mathrm{m}$. pronator teres weakly pronates the antebrachium, however, since antebrachial rotation is limited in L. pictus, its primary action may be to flex the antebrachium at the elbow.

M. flexor carpi radialis: This muscle is spindle-shaped. The cranial aspect of its distal half is covered by a thick aponeurosis near its origin (Fig. 8). The muscle originates from the medial epicondyle of the humerus (Fig. 5A). The caudal surface of the muscle is also covered by aponeurosis, adjacent to $\mathrm{m}$. flexor digitorum profundus caput humerale (Fig. 8). The muscle becomes tendinous at the distal half of the radius (Fig. 8). The proximal muscle fibers travel parallel to the radius, but at the midline of the muscle they converge distally as they form a tendon (Fig. 8). the tendon inserts onto the palmar aspects of the bases of metacarpals II and III. M. flexor carpi radialis flexes and stabilizes the carpal joint.

M. flexor carpi ulnaris: This muscle includes two heads.

M. flexor carpi ulnaris caput ulnare is short and flat, originating from the distomedial aspect of the olecranon (Figs. 6, 7). The muscle belly gives rise to a tendon at the level of the distal half of the ulna. The muscle fibers are oriented slightly obliquely toward the medial side. M. flexor carpi ulnaris caput ulnare caput ulnare lies superficial to $\mathrm{m}$. flexor digitorum profundus caput ulnare and is lateral to $\mathrm{m}$. flexor digitorum superficialis (Figs. 6, 7). It inserts on the pisiform (accessory carpal bone), cranial to the insertion of $\mathrm{m}$. flexor carpi ulnaris caput humerale (Figs. 11, 12). 
530

531

532

533

534

535

536

537

538

539

540

541

542

543

544

545

546

547

548

549

550

551

552

553

554

555

556

557

558

559

560

561

562

563

564

565

566

567

568
M. flexor carpi ulnaris caput humerale is flat proximally, becoming spindle-shaped in its distal half (Figs. 6,7). It originates from the caudal aspect of the medial epicondyle of the humerus (Figs. 4, 5). Fascia covers most of the muscle on its superficial and deep surfaces (Figs. $6,7)$. The muscle fibers are oriented parallel to the ulna, and the muscle inserts onto the pisiform, cranial to the insertion of $\mathrm{m}$. flexor carpi ulnaris caput humerale (Figs. 11, 12).

Together the two heads of $\mathrm{m}$. flexor carpi ulnaris flex and abduct the manus.

M. flexor digitorum superficialis: This muscle is spindle-shaped and somewhat flat (Fig. 8, 12). It is superficial to $\mathrm{m}$. flexor digitorum profundus and $\mathrm{m}$. flexor carpi ulnaris caput humerale (Fig. 8). The muscle originates from the medial epicondyle of the humerus (Fig. 5). The muscle becomes tendinous at the wrist and travels deep to the flexor retinaculum before passing medial to the pisiform (Fig. 11, 12). It then bifurcates over the proximal phalanges of digits II-V, allowing passage of $\mathrm{m}$. flexor digitorum profundus. The muscle inserts bilaterally on the palmar aspects of the middle phalanges of digits II-V (Fig. 11, 12). M. flexor digitorum superficialis flexes the carpal, metacarpophalangeal, and proximal interphalangeal joints of digits II-V.

M. flexor digitorum profundus: M. flexor digitorum profundus has five heads of various sizes, including three with a shared humeral origin, one ulnar, and one radial. It serves digits II-V and does not contact the vestigial digit I (Figs. 5, 8, 9, 10, 12).

Caput humerale laterale: This is the largest of the humeral heads, and accounts for approximately half of the entire humeral component, which has a fused origin (Fig. 8). It is spindle-shaped, with fibers that fan out from its origin at the caudodistal aspect of the medial epicondyle (Fig. 5). It lies adjacent to the caput humerale mediale, to the caput profundus, and deep to $\mathrm{m}$. flexor digitorum superficialis (Fig. 8). Approximately three fourths of the medial surface of the muscle is covered by parallel-fibered aponeurosis.

Caput humerale mediale: This is the most superficial of the humeral heads (Figs. 5, 8). It is spindle-shaped, covered by a thick aponeurosis, and about half the size of the caput humerale laterale. This medial head lies lateral to $\mathrm{m}$. flexor carpi radialis, medial to caput humerale laterale and $\mathrm{m}$. flexor digitorum superficialis, and superficial to caput humerale profundus.

Caput humerale profundus: This is the smallest humeral head. It is spindle-shaped and its fibers travel parallel to the ulna (Fig. 5). The medial aspect of its proximal half is covered by an aponeurosis. It gives rise to a tendon in the distal third of the radius, which is enclosed by the capita humerale laterale and mediale.

Caput ulnare: This belly lies caudal to the ulna (Fig. 9B). It originates from the base of the olecranon and the proximal quarter of the ulnar shaft (Fig. 9B). The entire muscle belly is slightly adhered via fascia to the ulna. Its tendon arises unattached to the bone, and joins the three humeral heads. The muscle's fibers are parallel to the ulna, and a thick aponeurosis covers the medial half of the superficial surface.

Peer) reviewing PDF | (2020:06:49981:1:1:NEW 29 Jul 2020) 
569

570

571

572

573

574

575

576

577

578

579

580

581

582

583

584

585

586

587

588

589

590

591

592

593

594

595

596

597

598

599

600

601

602

603

604

605

606

607

608

609
Caput radiale: This is the smallest head of $\mathrm{m}$. flexor digitorum profundus, located on the medial side of the antebrachium, superficial to $\mathrm{m}$. pronator quadratus. Its thin muscle belly originates from the proximal third of the caudomedial radius (Fig. 10A). The muscle fibers travel parallel to the radius, and the insertion tendon arises at the level of the distal quarter of the bone.

Tendons of the $\mathrm{m}$. flexor digitorum profundus fuse at the distalmost radius, and the combined tendon passes deep to the flexor retinaculum and medial to the pisiform. It divides into four smaller parts deep to the retinaculum, which serve digits II-V (Figs. 10, 11). The tendon of caput ulnare primarily serves digit $\mathrm{V}$, but such a distinction cannot be made for the tendons serving digits II-IV. M. flexor digitorum profundus flexes the carpal, metacarpophalangeal, proximal interphalangeal, and distal interphalangeal joints of digits II-V.

M. pronator quadratus: This muscle lies deep to $\mathrm{m}$. flexor digitorum profundus, occupying the entire space between the radius and ulna on the medial side of the antebrachium. It originates from the craniomedial aspect of the distal ulna and interosseous membrane (Fig. 9B). Its fibers are oriented obliquely to perpendicular to the radius and ulna. An aponeurosis covers the superficial surface of the proximal three quarters of the muscle belly. The muscle inserts on almost the entire caudomedial aspect of the radial shaft (Fig. 10). Unlike the muscle attachments in the domestic dog, these are situated more proximally on the radius and ulna (Evans \& de LaHunta, 2013). M. pronator quadratus weakly pronates, but likely primarily acts to stabilize the antebrachium.

\section{Muscles of the manus}

M. palmaris brevis: This muscle was not observed in L. pictus.

M. flexor digitorum brevis manus ( $m$. interflexorius): This muscle originates from a fascial sheet from $\mathrm{m}$. flexor digitorum profundus capita humerale mediale and laterale in the distal onequarter of the antebrachium (Fig. 12A). It lies on the palmar side of $\mathrm{m}$. flexor digitorum profundus, deep to $\mathrm{m}$. flexor digitorum superficialis, and it courses with the digital flexors through the carpus deep to the flexor retinaculum (Fig. 12A). The muscle belly is fusiform, becoming tendinous immediately proximal to the pisiform. the tendon splits and fuses onto the distal tendons of $\mathrm{m}$. flexor digitorum superficialis serving digits II-V inserting with the latter (Fig. 12A). This muscle therefore assists $\mathrm{m}$. flexor digitorum superficialis in flexing the carpal, metacarpophalangeal, and proximal interphalangeal joints of digits II-V.

Mm. lumbricales: These three thin muscles originate from the tendons of $\mathrm{m}$. flexor digitorum profundus. They are superficial to $\mathrm{mm}$. flexores breves profundi (Fig. 12A). The muscle fibers course parallel to the long axes of the metacarpals between adjacent tendons of $\mathrm{m}$. flexor digitorum profundus (Fig. 12A). The m. lumbricalis belly between the $\mathrm{m}$. flexor digitorum profundus tendons to digits III and IV is the largest, while the bellies between the tendons of digit II and III and between IV and V are smaller (Fig. 12A). The tendons of mm. lumbricales wrap dorsally to insert onto the medial sides of the extensor expansions of digits III-V (Fig. 
610 12A). The mm. lumbricales flex the metacarpophalangeal joints and extend the interphalangeal 611 joints of digits III-V.

612

613 Mm. adductores digitorum: The three $\mathrm{mm}$. adductores digitorum have adjacent origins from 614 the ligamentum carpi transversum before traveling to digits I, II, and V (Fig. 12B).

615 M. adductor digiti I ( $m$. adductor pollicis): This small belly originates from the 616 ligamentum carpi transversum cranial to $\mathrm{m}$. flexor brevis profundus to digit II (Fig. 12B). It is a

617 short, fan-shaped muscle that is wide at the origin and tapers at its insertion (Fig. 12B). It is 618 superficial to $\mathrm{m}$. flexor brevis profundus I and lateral to $\mathrm{m}$. abductor digiti I brevis and $\mathrm{m}$. flexor 619 digiti I brevis (Fig. 12B). It inserts onto the palmomedial surface of the vestigial first metacarpal 620 distal to the insertion of $\mathrm{m}$. abductor (et opponens) digiti I (Fig. 12B). As there appears to be 621 little mobility of the vestigial MC1, m. adductor digiti I may stabilize the reduced digit I.

622

623

624

M. adductor digiti II: This belly originates from the ligamentum carpi transversum

625

626

627

628

629

630

631

632

633

634

635

636

637

638

639

640

641

642

643

644

645

646

647

648

649

650

651

M. adductor digiti V: This muscle originates from the pisiform and center of the ligamentum carpi transversum on the palmar aspect of the carpometacarpal joint (Fig. 12B). It is a flat, fan-shaped muscle with slight aponeurosis on the proximal two-thirds of its palmar surface (Fig. 10B). It inserts onto the distomedial aspect of metacarpal $\mathrm{V}$ and partially attaches to the base of the proximal phalanx of digit $\mathrm{V}$ (Fig. 12B). M. adductor digiti $\mathrm{V}$ adducts digit $\mathrm{V}$ and weakly flexes the associated metacarpophalangeal and proximal interphalangeal joints.

Mm. flexores breves profundi ( $\mathrm{mm}$. interossei): The four $\mathrm{mm}$. flexores breves profundi originate from the bases of metacarpals II-V and also from the carpometacarpal joint capsules of digits II-V (Fig. 12B). They are located palmar to metacarpals II-V and lie deep to $\mathrm{mm}$. adductores digitorum, the tendons of $\mathrm{mm}$. flexor digitorum profundus and superficialis (Fig. 10B). At their distal third, each M. flexor brevis produndus splits into medial and lateral bellies that diverge to either side of the associated metacarpal (Fig. 12B). At the metacarpophalangeal joint, each belly abruptly becomes tendinous and inserts onto the medial and lateral proximal sesamoids (Fig. 12B). At the middle of metacarpal II, the tendons wrap collaterally to the dorsal side of the manus and fuse with the tendons of $\mathrm{m}$. extensor digitorum communis (Fig. 12B). This pattern was not observed in any other digit but may perhaps vary among individuals. The mm. flexores breves profundi flex the metacarpophalangeal joints of digits II-V. In those digits in which the tendons also insert onto the extensor expansion, they may also extend the interphalangeal joints. 
652

653

654

655

656

657

658

659

660

661

662

663

664

665

666

667

668

669

670

671

672

673

674

675

676

677

678

679

680

681

682

683

684

685

686

687

688

689

690

691

692

693

694

M. flexor digiti I brevis: This muscle originates from the flexor retinaculum proximal to the origin of $\mathrm{m}$. flexor brevis profundus to digit II (Fig. 12B). It is a short, thick muscle with muscle fibers travelling parallel to the metacarpals (Fig. 12B). Distally, it dives deep to the vestigial metacarpal I (Fig. 12B). Since minimal mobility is possible at the vestigial MC1, $\mathrm{m}$. flexor digiti I brevis may stabilize the reduced digit I.

M. abductor (et opponens) digiti I: This short, cylindrical muscle originates from the flexor retinaculum (Fig. 12B). It lies superficial to $\mathrm{m}$. flexor digiti I brevis and inserts onto fascia superficial to vestigial metacarpal I (Fig. 12B). Unlike in the domestic dog, there is no osseous insertion. Due to its lack of bony attachment, this muscle may weakly stabilize the wrist.

M. abductor digiti V: This is a small, flat muscle that arises from the distal aspect of the pisiform (Fig. 12B). Its fibers course obliquely and laterally from the pisiform to the lateral manus (Fig. 12B). The muscle produces a thin, transparent aponeurosis at the proximal quarter of metacarpal $\mathrm{V}$, which courses distally and inserts on the lateral base of the proximal phalanx of digit V (Fig. 12B). M. abductor digiti V abducts digit V and flexes the metacarpophalangeal joint.

M. flexor digiti V: This muscle originates from the flexor retinaculum of the pisiform. It is a small muscle that lies distal to the origin of $\mathrm{m}$. abductor digiti $\mathrm{V}$ and travels laterally over $\mathrm{m}$. flexor digitorum brevis digiti IV (Fig. 12B). The muscle becomes tendinous and fuses with the tendon of $\mathrm{m}$. abductor digiti $\mathrm{V}$, then inserts onto the base of the proximal phalanx of digit $\mathrm{V}$ (Fig. 12B). M. flexor digiti $\mathrm{V}$ flexes and abducts digit $\mathrm{V}$.

\section{Noteworthy Ligaments}

The ligaments of the upper limb of L. pictus were generally comparable to those of other published canids and are thus presented in detail in the Supplementary Information (Table S1). However, three notable ligamentous differences are worthy of full consideration here.

Membrana interossea antebrachii: This is a thick syndesmosis between the diaphyses of the radius and ulna. It courses along the entirety of both bones from immediately distal to the radial head through to the radiocarpal joint. The ligament holds the radius and ulna in a tight connection such that very little pronation or supination is possible. The membrane contained no apparent perforations for neurovasculature. The $\mathrm{m}$. pronator quadratus attaches along almost the entire length of the membrane.

Ligamentum interossei antebrachii: This short, thick ligament tightly connects the radius and ulna. At approximately one-third of the way along the antebrachium, it courses from a roughened area on the lateral radial shaft to a roughened area on the ulnar shaft. Its fibers run slightly obliquely distally. It is approximately $3.5 \mathrm{~cm}$ in length, substantially longer than the $2 \mathrm{~cm}$ length of the domestic dog. On the right side, it was partially ossified at its attachment to the ulna. As with the membrana interossea antebrachii, this ligament prevents rotatory movement of the radius around the ulna.

Peer] reviewing PDF | (2020:06:49981:1:1:NEW 29 Jul 2020) 
695 Ligamentum accessoriometacarpeum (pisimetacarpeum) $\mathbf{V}$ : This ligament is incredibly

696 robust, $5.3 \mathrm{~mm}$ thick and $18.5 \mathrm{~mm}$ long. It attaches proximally to the lateral surface of the

697 pisiform (accessory carpal bone). Its fibers course parallel to the orientation of the antebrachium

698 and attach distally to the lateral aspect of the base of metacarpal V (Fig. 11). Unlike the domestic

$699 \mathrm{dog}$, there is no attachment to metacarpal IV. This is the thickest and most powerful of the carpal

700 ligaments. The natural position of the carpal joint in L. pictus appears to be in a flexed position,

701 held tightly by the ligamenta accessoriometacarpea. The pisiform is more heavily involved in the

702 ligamentous apparatus of the carpus than in domestic dogs.

703

704 Discussion

\section{Vestigial digit I}

706

707

708

709

710

711

712

713

714

715

716

717

718

719

720

721

722

723

724

725

726

727

728

729

730

731

732

733

734

735

An unexpected finding of the present study was the presence of a small vestigial first metacarpal in L. pictus, challenging previous assumptions of complete tetradactyly in this species. While metacarpal I is diminutive and not associated with any phalanges, it still serves as the attachment site for several pollical muscles. Thus, we interpret L. pictus as being functionally, but not fully morphologically, tetradactyl.

. The absence of a first digit in L. pictus has been argued to facilitate increased speed and stride length (Creel and Creel, 2002; Chavez et al., 2019). The vestigial digit I of L. pictus lacks a claw and thus cannot grip the substrate during locomotion; however, the muscles associated with digit I may provide additional stability to the forefoot during endurance running. While early studies on energy expenditure estimated that energy costs for L. pictus during hunting are high (e.g., Gorman et al., 1998), recent studies based on more comprehensive models have concluded that hunting is less energetically costly for L. pictus than originally calculated (Hubel et al., 2016). Although L. pictus groups may travel an average of $14 \mathrm{~km}$ per day, including long-distance endurance chases (Hubel et al., 2016), they also utilize short high-speed bursts of opportunistic predation. These energetically efficient hunting opportunities effectively balance out the energy expended during exhaustive predation episodes. In another digitally reduced mammalian lineage, equidae, the vestigial second and fourth metacarpals serve an important function in supporting the articulation of the carpus and manus (e.g., Janis \& Bernor, 2019). Another possible function for the reduced pollical muscles in L. pictus is proprioception. The diminutive size of the muscle bellies suggests that they provide minimal mechanical leverage. However, muscles such as $\mathrm{m}$. abductor digiti I with its long thin tendon, may assist with proprioceptive functions around the carpal joint, which could be significantly advantageous during exhaustive predation.

\section{Quantitative forelimb muscle proportions}

The quantitative muscle proportion analyses indicated that canids generally possess relatively smaller pronators and supinators than felids, which is unsurprising given their divergent uses of the forelimb in locomotion and prey capture and manipulation. However, L. pictus is notable, even among canids, in its diminutive rotatory muscle mass. L. pictus has a smaller proportion of wrist rotators than any other comparative carnivoran taxon, followed by other large-bodied terrestrial taxa known to run and travel long distances. This finding supports the anatomical descriptive analyses which revealed a radius and ulna that were tightly adhered by a robust 
736

737

738

739

740

741

742

743

744

745

746

747

748

749

750

751

752

753

754

755

756

757

758

759

760

761

762

763

764

765

766

767

768

769

770

771

772

773

774

775

776

777

778

interosseous membrane and interosseous ligament. Minimal rotatory movement is possible between the radius and ulna in L. pictus suggesting adaptations for stability in the forelimb.

Additionally, the muscles associated with digit I were found to be reduced in L. pictus compared to all other taxa in the sample, exaggerating the reduced condition observed in other canids. In particular, mm. abductor digiti I and extensor digiti I et II are smaller and their attachments sites differ due to the absence of a full digit I. M. extensor digiti I et II does not insert onto the vestigial first digit, and instead possesses only a single tendon inserting onto digit II. While the belly of $\mathrm{m}$. abductor digiti I is broad, its tendon is gracile and thin, and has only a small attachment site onto the base of the vestigial metacarpal I.

The similarities in forelimb muscle proportions between L. pictus and the Dhole (Cuon alpinus) provide further insight into adaptations to cursoriality in canids. While not as highly cursorial as L. pictus, C. alpinus is also hypercarnivorous, hunts communally, and focuses on medium to large-bodied ungulates (Durbin et al., 2004). Most of its predatory chases are short, around 500 $\mathrm{m}$ (Fox, 1984), but it has been documented occasionally chasing prey for hours (Heptner \& Naumov, 1998). However, C. alpinus has a fully formed digit I (e.g., Castelló, 2018) making it an interesting comparative taxon. In both L. pictus and C. alpinus, $\mathrm{m}$. flexor digitorum profundus, $\mathrm{m}$. extensor digiti I et II, and abductor digiti I longus are reduced compared to all other included taxa, likely reflecting the reduced need for fine digital manipulation in these cursorial taxa. They also share relatively smaller mm. supinator and pronator teres, further supporting the interpretation that reduction of the rotatory muscles facilitates stability in the forelimb of long-distance runners. However, it should be noted that these reductions are more pronounced in L. pictus. The two species share an enlarged $\mathrm{m}$. supraspinatus, which is an important stabilizer of the glenohumeral joint and acts to prevent collapse of the shoulder (Goslow et al., 1981).

\section{Comparisons of qualitative muscular morphology to other published carnivoran taxa}

Musculature of the vestigial digit I:

The forelimb myology of L. pictus is generally similar to other canids; however, it displays some notable exceptions. The presence of a vestigial first metacarpal results in changes to insertions of $\mathrm{mm}$. extensor digiti I et II, adductor digiti I longus, abductor (et opponens) digiti I, and flexor digiti I brevis compared to other canids. The origin of $\mathrm{m}$. extensor digiti I et II is smaller than in the domestic dog, Canis familiaris (Evans \& de Lahunta, 2013) and pampas fox (de Sousa et al., 2018), and it inserts exclusively onto digit II, bypassing the vestigial digit I entirely.

Interestingly, the tendon of insertion still bifurcates, but rather than inserting onto digit I as in other canids, one tendon fuses with the insertion of extensor digitorum communis to digit II and the other inserts directly onto metatarsal II. Thus, the muscle does not act on the vestigial first digit. M. adductor digiti I longus of $L$. pictus has a substantially reduced origin compared to other canids, and its tendon of insertion onto metacarpal I is wispy and diminutive. It appears unlikely that it has sufficient leverage to move MC1.

Peer] reviewing PDF | (2020:06:49981:1:1:NEW 29 Jul 2020) 
779 Muscles and ligaments involved in forelimb stability and endurance running

780 The m. triceps brachii complex is expanded in L. pictus compared to other canids. In particular,

$781 \mathrm{~m}$. triceps brachii caput laterale has a larger origin in L. pictus compared to other carnivorans,

782 and $\mathrm{m}$. triceps brachii long head consist of two large bellies, referred to herein as caput longum

783 and caput magnum. Electromyographic (EMG) studies have shown that M. triceps brachii,

784 especially caput laterale, is active during the stance phase of trotting and galloping and is

785 important for storing elastic energy during locomotion (Goslow et al., 1981). Around the elbow,

$786 \mathrm{~m}$. anconeus also has a more extensive and proximal origin in L. pictus compared to other canids.

787 In addition to extending the elbow, this muscle plays an important role in resisting elbow flexion.

788 It is composed almost entirely of Type I fibers and has been suggested to provide proprioceptive

789 information about the elbow joint to the central nervous system (Buxton \& Peck, 1990).

790

791

792

793

794

795

796

797

798

799

800

801

802

803

804

805

806

807

808

809

810

M. brachialis has a more extensive origin in L. pictus than in other canids. In C. familiaris, this muscle has relatively high proportion of Type I "slow-twitch" fibers but is also electrically active during the swing phase of locomotion (Goslow et al., 1981). M. flexor carpi ulnaris caput ulnare of L. pictus is a larger muscle with a more extensive origin than C.familiaris. In domestic dogs, this muscle belly contains a large percentage (mean 77\%) of Type I muscle fibers, suggesting that it is resistant to fatigue (Armstrong et al., 1982). Also, in addition to its role in flexion of the forepaw with abduction, it has also been argued to play an important postural role in the forelimb (Evans and de Lahunta, 2013). While electromyographic studies and assessments of Type I versus Type II fibers in the forelimb muscles of L. pictus is out of the scope of the present study, it is reasonable to assume that the general patterns would not be dramatically divergent from those of $C$. familiaris. M. flexor digitorum profundus capita ulnare and radiale have smaller origins in L. pictus than all other comparative taxa, and the muscle's combined bellies have a smaller mass than most other comparative carnivoran taxa. This may reflect a reduced need for fine digital flexion. The mm. biceps brachii and brachialis appear to function as a unit, fusing distally to insert together onto both the radius and ulna. This pattern contrasts with the domestic dog in which the $\mathrm{m}$. brachialis tendon courses through a split in that of the $\mathrm{m}$. biceps brachii to insert exclusively onto the ulna (Fig 13). This difference may provide additional stability at the elbow joint in L. pictus. Overall, the forelimb muscles of L. pictus demonstrate a definitive pattern of stability and resistance to fatigue, with a concomitant reduction of rotatory movements, mobility of digit I, and fine digital flexion. The membrana interossea antebrachii and ligamentum interossei antebrachii are expanded compared to other canids, adhering the 812 radius and ulna tightly together.

813

814 The extensor and flexor muscles of the carpus in L. pictus are generally comparable in size and 815 attachments to other canids. However, the wrist is supported by an incredibly stout ligamentum 816 accesoriometacarpeum $\mathrm{V}$ attached to a prominently projecting pisiform, which may act as a strut 817 for assisting with passive flexion and rebound of the forefoot during sustained locomotion.

818 During touchdown of the manus, the carpus becomes extended passively due to gravity. The 819 natural tautness of the robust ligamentum accesoriometacarpeum $\mathrm{V}$ would tend to pull the wrist 820 back into flexion as soon as the forefoot starts leaving the ground, likely providing non-muscular 821 propulsion during push-off. This passive mechanism may help sustain endurance running and 
822 prevent the wrist muscles from tiring. This morphology displays apparent functional

823 convergence with the suspensory ligaments of the equid "spring foot". The equid suspensory

824 ligament is derived from the third interosseous muscle, and functions to support the forefoot and

825 provide passive "spring" action by absorbing and transferring forces experienced during

826 locomotion (McGuigan and Wilson, 2003). In the similarly cursorial L. pictus, the enlarged

827 ligamentum accesoriometacarpeum $\mathrm{V}$ may serve a comparable function.

828

829

We interpret these differences in size and attachments of muscles in L. pictus compared to other

830 canids as adaptations for long distance running in this highly cursorial species, likely important

831

832 for exhaustive predation. Absence of a complete digit I in L pictus, typically used to reduce

833

834

835 torque during quick turns and for lightly gripping onto objects, may be related to a reduced need for gripping and quick agile movements in its cursorial lifestyle.

836

837

838

839

840

841

842

843

844

\section{Limitations}

Finally, it must be acknowledged that this study is based on two limbs from a single captive specimen. Although this scenario is not ideal, specimens of this endangered species are extremely difficult to obtain. Thus, inferences must be drawn from a single individual that is assumed to be representative of the species. Of particular consideration are attachments sites of muscles which have been found to vary in other canids. For example, attachments of several palmar muscles display intraspecific variation in domestic dogs and Pampas fox (de Souza Junior et al., 2018). However, while we fully recognize the inability of the present study to evaluate intraspecific variation, the information presented herein may still inform future comparative studies of carnivoran adaptation and evolution. Future studies including additional L. pictus specimens may contribute to the understanding of variation in this taxon.

847 Conclusions

849

850

851

852

853

854

855

856

857

858

859

860

861

\section{2}

863

A vestigial first digit was discovered in L. pictus, in the form of a diminutive first metacarpal, demonstrating for the first time that this species is not fully tetradactyl. The forepaw is supported by a stout ligamentum accessoriometacarpeum $\mathrm{V}$, which holds the wrist in passive flexion. Wrist rotator muscles are reduced compared to other carnivorans, and robust interosseous ligaments bind the radius tightly to the ulna. Several muscles associated with joint stability and known to store elastic energy are expanded. The unexpected metacarpal I results in dramatic morphological alterations to associated digit I musculature. Natural tautness of ligamentum accessoriometacarpeum $\mathrm{V}$ may provide passive propulsion during the toe-off phase of locomotion, helping to sustain endurance running. These traits represent adaptations for long distance running and would facilitate exhaustive predation. We discuss the implications of the vestigial first metacarpal for the evolution of endurance running in Lycaon, suggesting that cursoriality may have evolved earlier than previously recognized.

\section{Acknowledgements}


864 The L. pictus specimen in this study was donated to the Arizona Research Collection for 865 Integrative Vertebrate Education and Study (ARCIVES) by the Arizona Center for Nature 866 Conservation/Phoenix Zoo. The authors wish to thank M. Taverne for generously sharing muscle 867 mass data for Cuon alpinus and Vulpes vulpes for the comparative analyses. We are grateful to 868 Drs. Suvi Viranta, Damian Ramoni, and Brandon Hedrick whose insightful comments improved 869 the manuscript. HFS would like to thank Dr. Kaye Reed for the introduction to this amazing 870 species in Kruger National Park in the summer of 2000. This is ARCIVES Publication \#4.

871

\section{References}

873 Armstrong RB, Saubert CWT, Seeherman HJ, Taylor CR. 1982. Distribution of fiber types in 874 locomotory muscles of dogs. American Journal of Anatomy 163(1):87-98.

875

876

877

878

879

880

881

882

883

884

885

886

887

888

889

890

891

892

893

894

895

896

897

898

899

900

901

902

903

904

905

Baryshnikov GF. 2012. Pleistocene Canidae (Mammalia, Carnivora) from the Paleolithic Kudaro caves in the Caucasus. Russian Journal of Theriology 11(2): 77-120.

Buxton DF, Peck D. 1990. Density of muscle spindle profiles in the intrinsic forelimb muscles of the dog. Journal of Morphology 203: 345-359.

Castello JR. 2018. Canids of the World. Princeton University Press: Princeton, New Jersey.

Chavez DE, Gronau I, Hains T, Kliver S, Koepfli KP, Wayne, RK. 2019. Comparative genomics provides new insights into the remarkable adaptations of the African wild dog (Lycaon pictus). Scientific Reports 9:1-14.

Cherin M, Bertè DF, Rook L, Sardella R. 2013. Re-defining Canis etruscus (Canidae, Mammalia): A new look into the evolutionary history of Early Pleistocene dogs resulting from the outstanding fossil record from Pantalla (Italy). Journal of Mammalian Evolution 21: 95110 .

Creel S, Creel NM. 2002. The African wild dog: behavior, ecology and conservation. Princeton University Press, Princeton, NJ.

Creel S, Marusha NC.1998. Six ecological factors that may limit African wild dogs, Lycaon pictus. Animal Conservation 1: 1-9.

Davis DD. 1964. The giant panda: A morphological study of evolutionary mechanisms. Fieldiana Zoology Memoirs 3: 1-339.

de Souza Junior P, Santos LMRPD, Viotto-Souza W, de Carvalho NDC, Souza EC, Kasper CB, Abidu-Figueiredo M, Santos ALQ. 2018. Functional myology of the thoracic limb in Pampas fox (Lycalopex gymnocercus): a descriptive and comparative analysis. Journal of Anatomy 233(6): 783-806.

906 
907 Durbin LS, Venkataraman A, Hedges S, Duckworth W. 2004. Dhole Cuon alpinus (Pallas 1811). 908 In Sillero-Zubiri C, Hoffmann M, Macdonald DW (eds.): Canids: Foxes, Wolves, Jackals and 909 Dogs. Status Survey and Conservation Action Plan. Gland, Switzerland; Cambridge, UK:

910 911

912

913

914

915

916

917

918

919

920

921

922

923

924

925

926

927

928

929

930

931

932

933

934

935

936

937

938

939

940

941

942

943

944

945

IUCN/SSC Canid Specialist Group. pp. 210-219.

Ercoli MD, Álvarez A, Stefanini MI, Busker F, Morales M. 2015. Muscular anatomy of the forelimbs of the lesser grison (Galictis cuja), and a functional and phylogenetic overview of mustelidae and other caniformia. Journal of Mammalian Evolution 22: 57-91.

Evans HE, de Lahunta A. 2013. Miller's Anatomy of the Dog, 4th ed. Elsevier Health Sciences, St. Louis, MO.

Facer T. 2017. Forelimb myology of the kinkajou (Potos flavus). Unpublished Master's thesis, Midwestern University, Glendale, AZ.

Farrand WR, McMahon JP. 1997. History of the sedimentary infilling of Yarimburgaz Cave, Turkey. Geoarchaeology 12(6): 537-565.

Fisher RE, Adrian B, Barton M, Holmgren J, Tang S. 2009. The phylogeny of the red panda (Ailurus fulgens): evidence from the forelimb. Journal of Anatomy 215: 611-635.

Fox CH, Johnson FB, Whiting J and Roller PP. 1985. Formaldehyde fixation. Journal of Histochemistry and Cytochemistry 33:845-853.

Fox MW. 1984. The Whistling Hunters: Field Studies of the Asiatic Wild Dog (Cuon Alpinus). Albany: State University of New York Press.

Gorman M, Mills MG, Raath JP, Speakman JR. 1998. High hunting costs make African wild dogs vulnerable to kleptoparasitism by hyaenas. Nature 391:479-481.

Goslow GE, Seeherman HJ, Taylor CR, McCutchin MN, Heglund NC. 1981. Electrical activity and relative length changes of dog limb muscles as a function of speed and gait. Journal of Experimental Biology 94:15-42.

Hartstone-Rose A, Werdelin L, De Ruiter DJ, Berger LR, Churchill SE. 2010. The PlioPleistocene ancestor of wild dogs, Lycaon sekowei n. sp. Journal of Paleontology 84 (2):299308. doi:10.1666/09-124.1.

Heptner VG, Naumov NP. 1998. Genus Cuon Hodgson, 1838. In: Mammals of the Soviet Union. II. Part 1A: Sirenia and Carnivora (Sea Cows, Wolves, and Bears). Washington, DC: Smithsonian Institution and National Science Foundation. pp. 566-586.

Hubel TY, Myatt JP, Jordan NR, Dewhirst OP, McNutt JW, Wilson AM. 2016. Energy cost and return for hunting in African wild dogs and cheetahs. Nature Communications 7:11034. doi: $10.1038 /$ ncomms 11034

PeerJ reviewing PDF | (2020:06:49981:1:1:NEW 29 Jul 2020) 
946 Janis CM, Bernor RL. 2019. The evolution of equid monodactyly: A review including a new 947 hypothesis. Frontiers in Ecology and Evolution 7:119.

948 Julik E, Zack S, Adrian B, Maredia S, Parsa A, Poole M, Starbuck A, Fisher RE. 2012.

949 Functional Anatomy of the Forelimb Muscles of the Ocelot (Leopardus pardalis). Journal of

950 Mammalian Evolution 19: 277-304.

951 Kurtén B. 1968. Pleistocene Mammals of Europe: 317 pp., Aldine Publishing Company, London.

952 Lindblad-Toh KC, Wade M, Mikkelsen EK, Karlsson D, Jaffe B, Kamal M, Clamp M, Chang, 953 JL, Kulnokas III EJ, Zody MC, Mauceli E, Xie X, Breen M, Wayne RK, Ostrander EA, 954 Ponting CP, Galibert F, Smith DR, Dejong PJ, Kirkness E, Alvarez E, Biagi T, Brockman W, 955 Butler J, Chin C-W, Cook A, Cuff J, Daly MJ, Decaprio D, Gnerre S, Grabherr M, Kellis M, 956 Kleber M, Bardeleben C, Goodstadt L, Heger A, Hitte C, Kim L, Koepfli K-P, Parker HG, 957 Pollinger JP, Searle SMJ, Sutter NB, Thomas R, Webber C, Lander ES. 2005. Genome 958 sequence, comparative analysis and haplotype structure of the domestic dog. Nature 438: 803959819

960

961

962

963

964

965

966

967

968

969

970

971

972

973

974

975

976

McGuigan MP, Wilson AM. 2003. The effect of gait and digital flexor muscle activation on limb compliance in the forelimb of the horse Equus caballus. Journal of Experimental Biology 206: $1325-1336$.

McNutt JW. 2008. Lycaon pictus. IUCN Red List of Threatened Species. Version 2008.

Mendez J, Keys A, Anderso, JT, Grand, F. 1960. Density of fat and bone mineral of the mammalian body. Metabolism 9: 472-477.

Moulle PE, Echassoux A, Lacombat F. 2006. Taxonomie du grand canidé de la grotte du Vallonnet (Roquebrune-Cap-Martin, Alpes-Maritimes, France). L'Anthropologie 110(5): 832836.

Rook L. 1994. The Plio-Pleistocene old world Canis (Xenocyon) ex gr. Falconeri. Bollettino della Società Paleontologica Italiana 33: 71-82.

Stiner MC, Howell FC, Martínez-Navarro B, Tchernov E, Bar-Yosef O. 2001. Outside Africa: Middle Pleistocene Lycaon from Hayonim Cave, Israel. Bolletino della Società Paleontologica Italiana 40(2): 293-302.

977

Taverne M, Fabre A-C, Herbin M, Herrel A, Peigne S, Lacroux C, Lowie A, Pages F, Theil J-C,

978 Bohmer C. 2018. Convergence in the functional properties of forelimb muscles in carnivorans:

979

980

981 adaptations to an arboreal lifestyle? Biological Journal of the Linnean Society 125: 250-263.

982

Toh K, Wade CM, Mikkelsen TS, Karlsson EK, Jaffe DB. 2005. Genome sequence, comparative analysis and haplotype structures of the domestic dog. Nature 438: 803-819. 
983 Van Valkenburgh B. 1987. Skeletal indicators of locomotor behavior in living and extinct

984 carnivores. Journal of Vertebrate Paleontology 7: 162-182.

985 Viranta S, Lommi H, Holmala K, Laakkonen J. 2016. Musculoskeletal anatomy of the Eurasian 986 lynx, Lynx lynx (Carnivora: Felidae) forelimb: Adaptations to capture large prey? Journal of 987 Morphology 277: 753-765.

988

989

990

991

992

993

994

995

996

997

998

999

1000

1001

1002

1003

1004

1005

Walker RH, King AJ, McNutt JW, Jordan NR. 2017. Sneeze to leave: African wild dogs (Lycaon pictus) use variable quorum thresholds facilitated by sneezes in collective decisions. Proceedings of the Royal Society of London B 284(1862): 20170347.

Wayne, R. K. 1993. Molecular evolution of the dog family. Trends in Genetics 9(6): 218-224.

Woodroffe R, Lindsey PA, Romañach SS, Ranah SMO. 2007. African wild dogs (Lycaon pictus) can subsist on small prey: implications for conservation. Journal of Mammalogy 88(1): 181193.

Woodroffe R, McNutt JW, Mills MGL. 2004. African Wild Dog Lycaon pictus. In: SilleroZubiri C, Hoffman M, MacDonald DW, ed., Canids: Foxes, Wolverhampton Wanderers F.C., Jackals and Dogs - 2004 Status Survey and Conservation Action Plan, 174-183. IUCN/SSC Canid Specialist Group.

Woodroffe R, Sillero-Zubiri C. 2012. Lycaon pictus. The IUCN Red List of Threatened Species 2012: e.T12436A16711116. Retrieved 02/10/2018. 


\section{Figure Captions}

1007 Figure 1. Regression plot of relative proportions of wrist rotator functional group to elbow 1008 extensor functional group in $L$. pictus and the comparative carnivoran sample (Taverne et al., 1009 2018). Note the position of $L$. pictus which has the smallest wrist rotator group in the sample.

1010 Figure 2. Medial view of the right shoulder and brachium in Lycaon pictus.

1011 Figure 3. Scapula muscle maps for $L$. pictus (right side): (A) lateral view; (B) medial view.

1012 Figure 4. Lateral view of the right shoulder and brachium in L. pictus.

1013 Figure 5. Humerus muscle maps for L. pictus (right side): (A) medial view; (B) lateral view.

1014 Figure 6. Lateral view of the superficial right antebrachium in L. pictus, including $\mathrm{mm}$. biceps 1015 brachii, brachialis, and anconeus.

1016 Figure 7. Lateral view of the deep right antebrachium in L. pictus.

1017 Figure 8. Medial view of the right antebrachium in L. pictus, including mm. biceps brachii and 1018 brachioradialis.

1019 Figure 9. Ulna muscle maps for $L$. pictus (right side): (A) lateral view; (B) medial view.

1020 Figure 10. Radius muscle maps for $L$. pictus (right side): (A) medial view; (B) lateral view. Figure 11. Dorsal manus muscle maps for $L$. pictus (right side).

Figure 12. Palmar view of manus muscles in L. pictus (right side): (A) superficial view; (B) deep view.

Figure 13. Insertions of $\mathrm{mm}$. biceps brachii and brachialis: (A) photograph of Lycaon pictus; (B) illustration of $L$. pictus; (C) illustration of Canis familiaris. Numbers indicate: $3=\mathrm{m}$. biceps brachii; $9=\mathrm{m}$. brachialis; $42=\mathrm{m}$. flexor digitorum superficialis; $43=\mathrm{m}$. flexor digitorum profundus; $44=\mathrm{m}$. flexor carpi radialis. Note that in $L$. pictus, the tendons of $\mathrm{mm}$. biceps brachii and brachialis fuse to insert together onto both the radius and ulna, while in $C$. familiaris $\mathrm{m}$. brachialis tendon travels through a split in the tendon of $\mathrm{m}$. biceps brachii to insert exclusively onto the ulna. 


\section{Table $\mathbf{1}$ (on next page)}

Quantitative data on forelimb muscles of the adult male Lycaon pictus specimen dissected in the present study. 
1 Table 1.

\begin{tabular}{|c|c|c|}
\hline Muscle & Mass (g) & Proportion (\%) \\
\hline M. acromiodeltoideus & 19.0 & 0.0233 \\
\hline M. spinodeltoideus & 23.0 & 0.0282 \\
\hline M. supraspinatus & 124.0 & 0.1522 \\
\hline M. infraspinatus & 95.0 & 0.1166 \\
\hline M. subscapularis & 75.0 & 0.0921 \\
\hline M. teres major & 34.0 & 0.0417 \\
\hline M. teres minor & 5.0 & 0.0061 \\
\hline M. biceps brachii & 32.0 & 0.0393 \\
\hline M. brachialis & 18.0 & 0.0221 \\
\hline M. triceps brachii & 240.0 & 0.2947 \\
\hline M. anconeus & 5.0 & 0.0061 \\
\hline M. brachioradialis & 10.0 & 0.0123 \\
\hline M. extensor carpi ulnaris & 13.0 & 0.0160 \\
\hline M. extensor digitorum lateralis & 5.0 & 0.0061 \\
\hline M. extensor digitorum communis & 10.0 & 0.0123 \\
\hline M. extensor digiti I and II & 0.5 & 0.0006 \\
\hline M. abductor digiti I longus & 1.0 & 0.0012 \\
\hline M. extensor carpi radialis- longus + brevis & 27.0 & 0.0331 \\
\hline M. supinator & 0.5 & 0.0006 \\
\hline M. pronator teres & 1.0 & 0.0012 \\
\hline M. palmaris longus & 16.0 & 0.0196 \\
\hline M. flexor carpi ulnaris, ulnar head & 6.0 & 0.0074 \\
\hline M. flexor carpi ulnaris, humeral head & 14.0 & 0.0172 \\
\hline M. flexor carpi radialis & 6.0 & 0.0074 \\
\hline M. flexor digitorum profundus & 43.0 & 0.0528 \\
\hline M. pronator quadratus & 0.5 & 0.0006 \\
\hline Total mass of included muscles & 814.5 & 1.0000 \\
\hline
\end{tabular}




\section{Table 2 (on next page)}

Volumes and relative proportions of functional forelimb muscle groups in Lycaon pictus and comparative carnivoran taxa (Taverne et al., 2018).

L. pictus has the lowest proportion of wrist rotators and among the largest elbow extensors in the sample (values indicated in bold). 
1 Table 2.

\begin{tabular}{|c|c|c|c|c|c|c|c|c|c|c|c|}
\hline Taxon & Sum & $\begin{array}{l}\text { Elbow } \\
\text { extens } \\
\text { ors }\end{array}$ & $\begin{array}{l}\text { Elbow } \\
\text { flexors }\end{array}$ & $\begin{array}{l}\text { Wrist } \\
\text { exten } \\
\text { sors }\end{array}$ & $\begin{array}{l}\text { Wrist } \\
\text { flexor } \\
\text { s }\end{array}$ & $\begin{array}{l}\text { Wrist } \\
\text { rotato } \\
\text { rs }\end{array}$ & $\begin{array}{l}\text { Elbow } \\
\text { extenso } \\
\text { rs- } \\
\text { proporti } \\
\text { on }\end{array}$ & $\begin{array}{l}\text { Elbow } \\
\text { flexors- } \\
\text { proporti } \\
\text { on }\end{array}$ & $\begin{array}{l}\text { Wrist } \\
\text { extens } \\
\text { ors- } \\
\text { proport } \\
\text { ion }\end{array}$ & $\begin{array}{l}\text { Wrist } \\
\text { flexors- } \\
\text { proport } \\
\text { ion }\end{array}$ & $\begin{array}{l}\text { Wrist } \\
\text { rotators } \\
\text { - } \\
\text { proporti } \\
\text { on }\end{array}$ \\
\hline $\begin{array}{l}\text { Lycaon } \\
\text { pictus }\end{array}$ & $\begin{array}{l}554.7 \\
2\end{array}$ & 318.87 & 99.06 & 52.83 & 80.19 & 3.77 & $0.575^{*}$ & 0.179 & 0.095 & 0.145 & $0.007^{*}$ \\
\hline $\begin{array}{l}\text { Mustela } \\
\text { putorius }\end{array}$ & 24.62 & 12.68 & 3.86 & 2.46 & 4.53 & 1.09 & 0.515 & 0.157 & 0.100 & 0.184 & 0.044 \\
\hline $\begin{array}{l}\text { Vulpes } \\
\text { vulpes }\end{array}$ & $\begin{array}{l}144.0 \\
7\end{array}$ & 87.70 & 22.82 & 12.42 & 19.06 & 2.07 & 0.609 & 0.158 & 0.086 & 0.132 & 0.014 \\
\hline $\begin{array}{l}\text { Herpestes } \\
\text { auropunctatu } \\
s\end{array}$ & 5.25 & 2.89 & 0.79 & 0.52 & 0.79 & 0.26 & 0.550 & 0.150 & 0.099 & 0.150 & 0.050 \\
\hline Procyon lotor & 34.52 & 16.93 & 6.68 & 3.40 & 5.67 & 1.84 & 0.490 & 0.194 & 0.098 & 0.164 & 0.053 \\
\hline $\begin{array}{l}\text { Acinonyx } \\
\text { jubatus }\end{array}$ & $\begin{array}{l}1060 . \\
2\end{array}$ & 606.00 & 209.00 & 83.00 & 136.20 & 26.00 & 0.572 & 0.197 & 0.078 & 0.128 & 0.025 \\
\hline $\begin{array}{l}\text { Martes } \\
\text { martes }\end{array}$ & 41.86 & 21.58 & 7.14 & 4.16 & 7.13 & 1.85 & 0.516 & 0.171 & 0.099 & 0.170 & 0.044 \\
\hline Martes foina & 31.31 & 16.00 & 5.14 & 3.25 & 5.35 & 1.57 & 0.511 & 0.164 & 0.104 & 0.171 & 0.050 \\
\hline Meles meles & $\begin{array}{l}250.0 \\
4\end{array}$ & 134.94 & 33.12 & 22.24 & 48.81 & 10.93 & 0.540 & 0.132 & 0.089 & 0.195 & 0.044 \\
\hline $\begin{array}{l}\text { Galidia } \\
\text { elegans }\end{array}$ & 12.03 & 6.52 & 1.99 & 1.12 & 1.96 & 0.44 & 0.542 & 0.165 & 0.093 & 0.163 & 0.037 \\
\hline $\begin{array}{l}\text { Cryptoprocta } \\
\text { ferox }\end{array}$ & 64.06 & 31.74 & 11.18 & 6.83 & 10.62 & 3.69 & 0.495 & 0.175 & 0.107 & 0.166 & 0.058 \\
\hline $\begin{array}{l}\text { Paradoxurus } \\
\text { hermaphrodit } \\
\text { us }\end{array}$ & 34.97 & 16.47 & 6.80 & 3.84 & 5.04 & 2.82 & 0.471 & 0.194 & 0.110 & 0.144 & 0.081 \\
\hline Potos flavus & 42.09 & 18.52 & 8.21 & 4.52 & 8.07 & 2.77 & 0.440 & 0.195 & 0.107 & 0.192 & 0.066 \\
\hline Cuon alpinus & $\begin{array}{l}496.9 \\
2\end{array}$ & 293.00 & 76.00 & 42.49 & 78.00 & 7.43 & 0.590 & 0.153 & 0.086 & 0.157 & 0.015 \\
\hline $\begin{array}{l}\text { Hyaena } \\
\text { hyaena }\end{array}$ & 1162 & 661.00 & 201.00 & $\begin{array}{l}105.9 \\
0\end{array}$ & 181.00 & 13.10 & 0.569 & 0.173 & 0.091 & 0.156 & 0.011 \\
\hline Nasua nasua & 54.97 & 25.43 & 9.03 & 4.41 & 12.83 & 3.27 & 0.463 & 0.164 & 0.080 & 0.233 & 0.059 \\
\hline $\begin{array}{l}\text { Felis } \\
\text { silvestris } \\
\text { catus }\end{array}$ & 42.4 & 20.75 & 8.44 & 5.39 & 6.27 & 1.55 & 0.489 & 0.199 & 0.127 & 0.148 & 0.037 \\
\hline $\begin{array}{l}\text { Arctictis } \\
\text { binturong }\end{array}$ & 434 & 237.40 & 72.90 & 35.20 & 63.90 & 24.60 & 0.547 & 0.168 & 0.081 & 0.147 & 0.057 \\
\hline
\end{tabular}




\section{Table 3 (on next page)}

Relative proportions of individual forelimb muscles in L. pictus and comparative sample.

Comparative data were taken from Julik et al., 2012 (Leopardus pardalis), Ercoli et al. 2015

(Galictis cuja), Viranta et al. 2016 (Lynx lynx), and Taverne et al. 2018 (Cuon alpinus and Vulpes vulpes). 
1 Table 3.

\begin{tabular}{|c|c|c|c|c|c|c|}
\hline Muscle & $\begin{array}{l}\text { Lycaon } \\
\text { pictus }\end{array}$ & $\begin{array}{l}\text { Cuon } \\
\text { alpinus }\end{array}$ & $\begin{array}{l}\text { Vulpes } \\
\text { vulpes }\end{array}$ & $\begin{array}{l}\text { Galictis } \\
\text { cuja }\end{array}$ & $\begin{array}{l}\text { Leopardus } \\
\text { pardalis }\end{array}$ & Lynx lynx \\
\hline Taxonomic group & Caniformia & Caniformia & Caniformia & Caniformia & Feliformia & Feliformia \\
\hline $\begin{array}{l}\text { M. } \\
\text { acromiodeltoideus }\end{array}$ & 0.0233 & 0.0191 & 0.0147 & 0.0193 & 0.0199 & 0.0195 \\
\hline M. spinodeltoideus & 0.0282 & 0.0143 & 0.0273 & 0.0126 & 0.0244 & 0.0211 \\
\hline M. supraspinatus & 0.1522 & 0.1561 & 0.1161 & 0.1184 & 0.1243 & 0.1069 \\
\hline M. infraspinatus & 0.1166 & 0.0860 & 0.0883 & 0.0525 & 0.0990 & 0.0742 \\
\hline M. subscapularis & 0.0921 & 0.0780 & 0.0899 & 0.0744 & 0.1457 & 0.0838 \\
\hline M. teres major & 0.0417 & 0.0350 & 0.0484 & 0.0172 & 0.0664 & 0.0639 \\
\hline M. teres minor & 0.0061 & 0.0023 & 0.0054 & 0.0009 & 0.0066 & 0.0048 \\
\hline M. biceps brachii & 0.0393 & 0.0398 & 0.0390 & 0.0368 & 0.0635 & 0.0643 \\
\hline M. brachialis & 0.0221 & 0.0191 & 0.0208 & 0.0340 & 0.0238 & 0.0278 \\
\hline M. triceps combined & 0.2947 & 0.3328 & 0.3586 & 0.3392 & 0.1935 & 0.2581 \\
\hline M. anconeus & 0.0061 & 0.0096 & 0.0074 & 0.0081 & 0.0177 & 0.0084 \\
\hline M. brachioradialis & 0.0123 & 0.0000 & 0.0000 & 0.0172 & 0.0085 & 0.0033 \\
\hline $\begin{array}{l}\text { M. extensor carpi } \\
\text { ulnaris }\end{array}$ & 0.0160 & 0.0159 & 0.0117 & 0.0221 & 0.0181 & 0.0156 \\
\hline $\begin{array}{l}\text { M. extensor } \\
\text { digitorum lateralis }\end{array}$ & 0.0061 & 0.0064 & 0.0049 & 0.0095 & 0.0064 & 0.0083 \\
\hline $\begin{array}{l}\text { M. extensor } \\
\text { digitorum communis }\end{array}$ & 0.0123 & 0.0127 & 0.0127 & 0.0134 & 0.0100 & 0.0196 \\
\hline $\begin{array}{l}\text { M. extensor digiti I } \\
\text { and II }\end{array}$ & 0.0006 & 0.0008 & 0.0012 & 0.0032 & 0.0021 & 0.0000 \\
\hline $\begin{array}{l}\text { M. abductor digiti I } \\
\text { longus }\end{array}$ & 0.0012 & 0.0048 & 0.0064 & 0.0124 & 0.0125 & 0.0122 \\
\hline $\begin{array}{l}\text { M. extensor carpi } \\
\text { radialis- longus + } \\
\text { brevis }\end{array}$ & 0.0331 & 0.0271 & 0.0342 & 0.0321 & 0.0256 & 0.0358 \\
\hline M. supinator & 0.0006 & 0.0021 & 0.0020 & 0.0074 & 0.0082 & 0.0054 \\
\hline M. pronator teres & 0.0012 & 0.0048 & 0.0065 & 0.0197 & 0.0199 & 0.0163 \\
\hline M. palmaris longus & 0.0196 & 0.0255 & 0.0215 & 0.0266 & 0.0247 & 0.0228 \\
\hline M. flexor carpi & 0.0074 & 0.0239 & 0.0045 & 0.0254 & 0.0080 & 0.0057 \\
\hline
\end{tabular}




\begin{tabular}{|l|l|l|l|l|l|l|}
\hline ulnaris, ulnar head & & & & & & \\
\hline $\begin{array}{l}\text { M. flexor carpi } \\
\text { ulnaris, humeral } \\
\text { head }\end{array}$ & 0.0172 & 0.0064 & 0.0126 & 0.0146 & 0.0108 & 0.0159 \\
\hline $\begin{array}{l}\text { M. flexor carpi } \\
\text { radialis }\end{array}$ & 0.0074 & 0.0064 & 0.0059 & 0.0077 & 0.0077 & 0.0133 \\
\hline $\begin{array}{l}\text { M. flexor digitorum } \\
\text { profundus }\end{array}$ & 0.0528 & 0.0621 & 0.0518 & 0.0716 & 0.0502 & 0.0643 \\
\hline $\begin{array}{l}\text { M. pronator } \\
\text { quadratus }\end{array}$ & 0.0006 & 0.0050 & 0.0036 & 0.0029 & 0.0059 & 0.0045 \\
\hline $\begin{array}{l}\text { Total mass of } \\
\text { included muscles }\end{array}$ & $\mathbf{8 1 4 . 5 0}$ & $\mathbf{6 2 7 . 9 7}$ & $\mathbf{1 7 2 . 7 0}$ & $\mathbf{9 7 . 5 8}$ & $\mathbf{2 5 8 . 8 3}$ & $\mathbf{6 2 6 . 0 9}$ \\
\hline
\end{tabular}

2 
Figure 1

Regression plot of relative proportions of wrist rotator functional group to elbow extensor functional group in L. pictus and the comparative carnivoran sample (Taverne et al., 2018).

Note the position of $L$. pictus which has the smallest wrist rotator group in the sample.

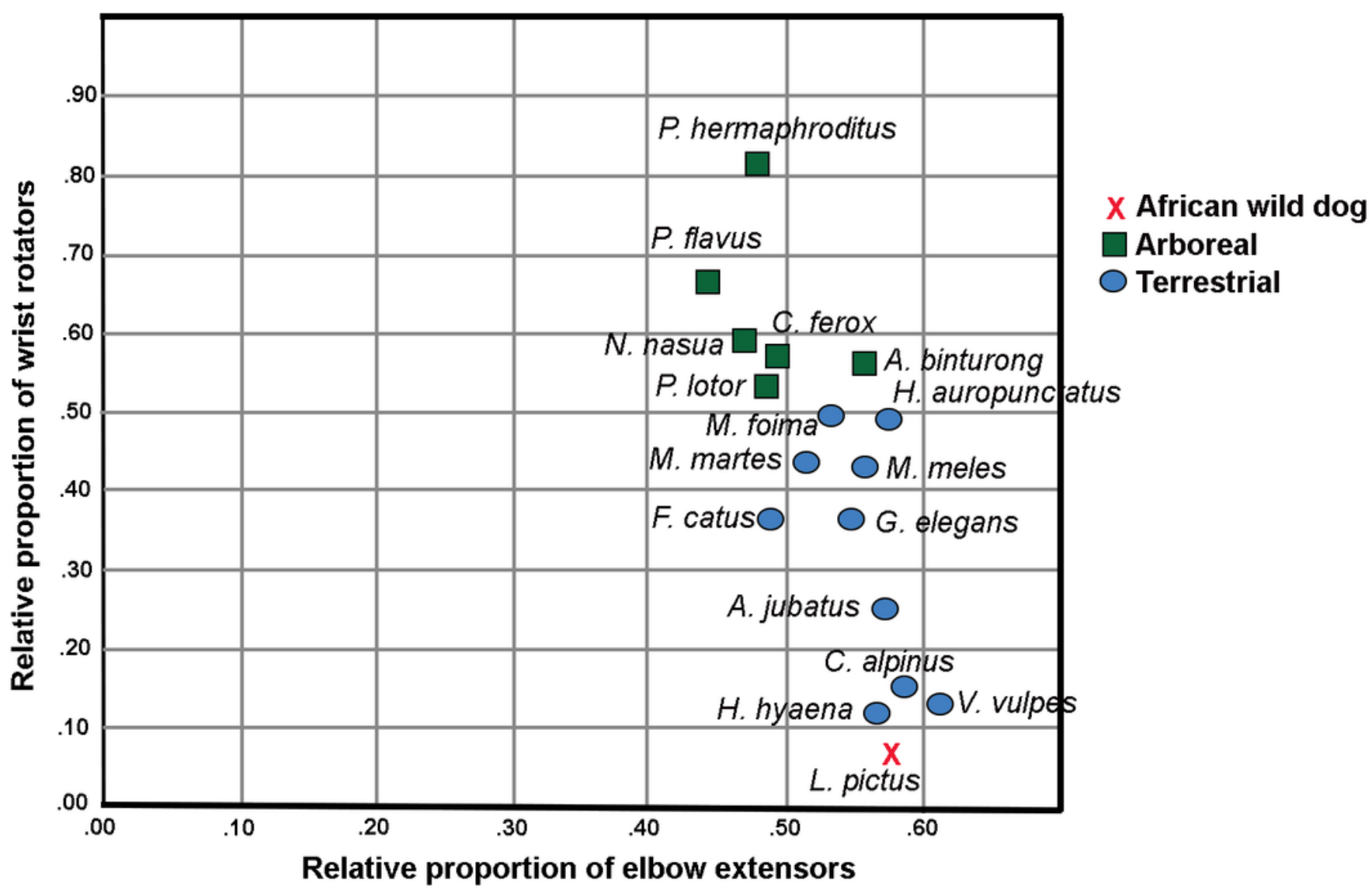


Figure 2

Medial view of the right shoulder and brachium in Lycaon pictus. 


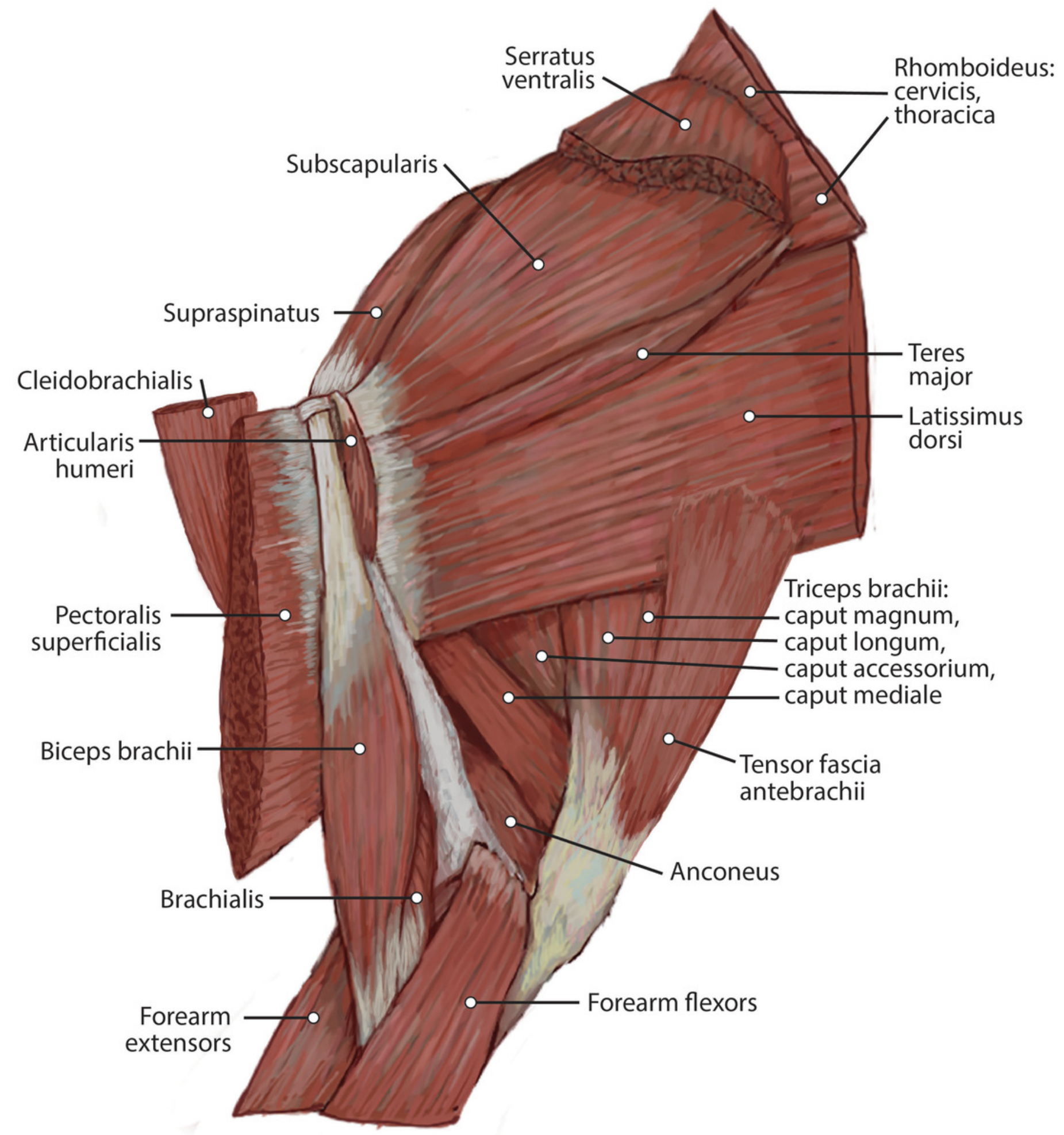




\section{Figure 3}

Scapula muscle maps for L. pictus (right side): (A) lateral view; (B) medial view.

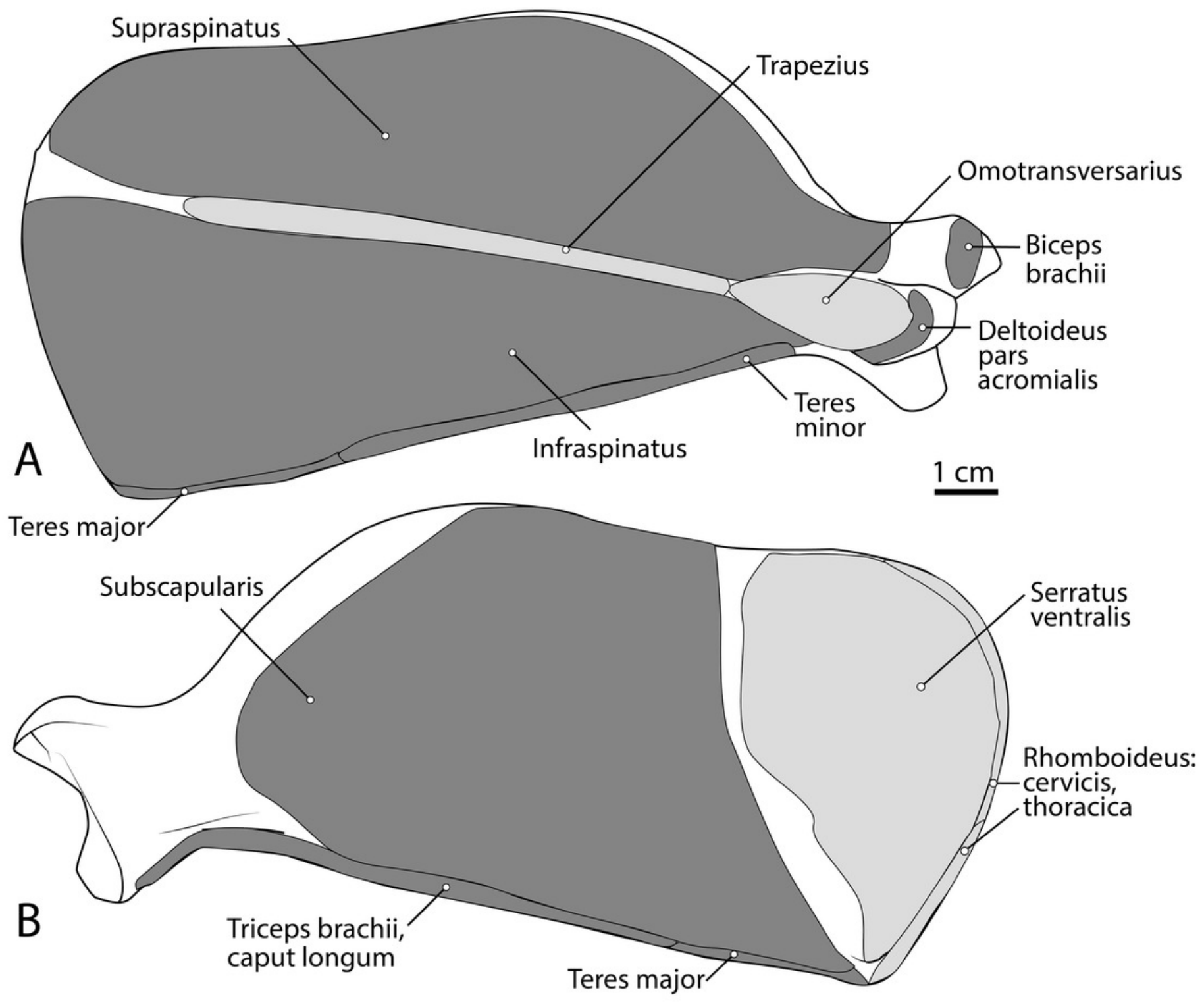


Figure 4

Lateral view of the right shoulder and brachium in L. pictus.

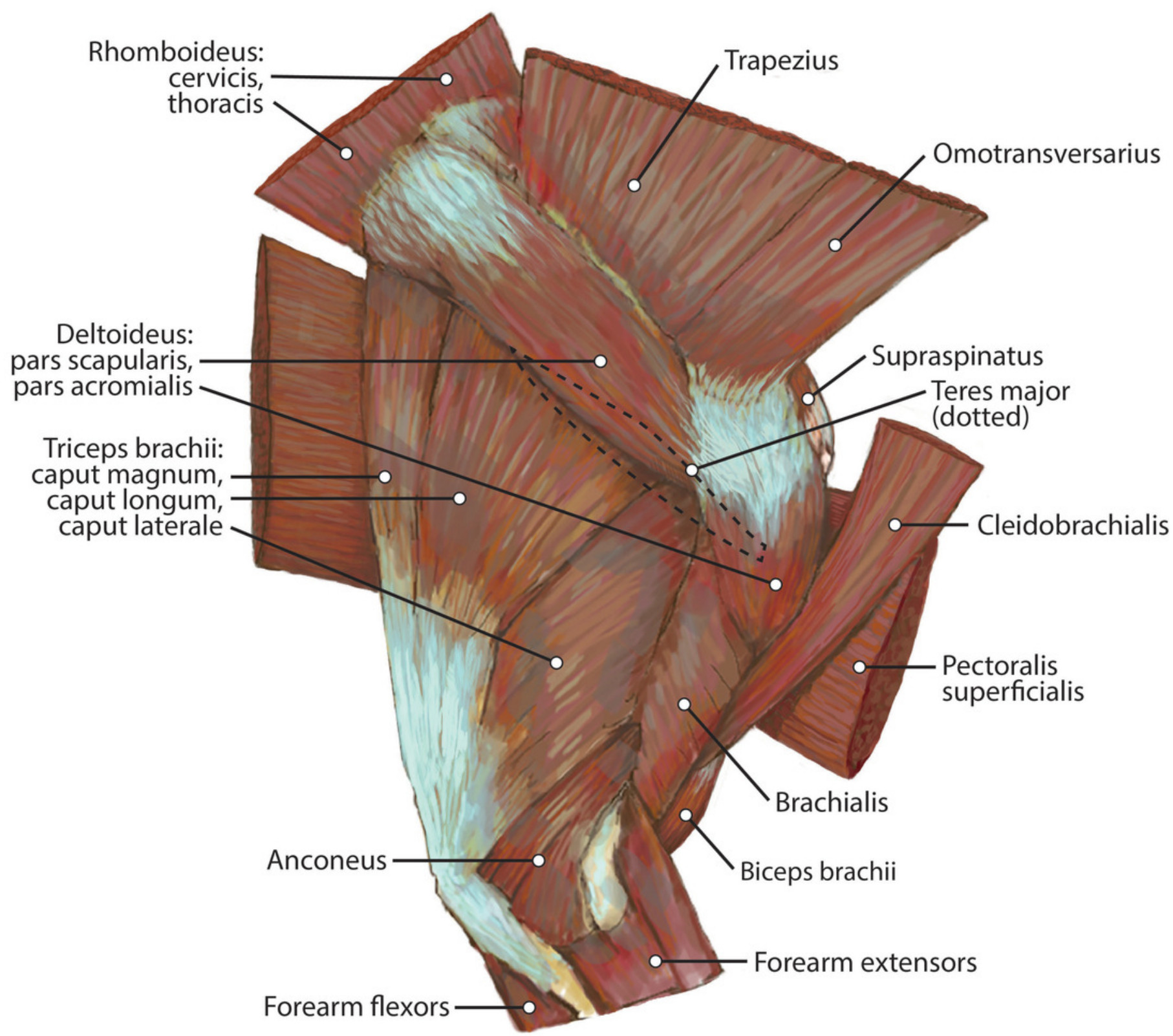


Figure 5

Humerus muscle maps for $L$. pictus (right side): (A) medial view; (B) lateral view. 


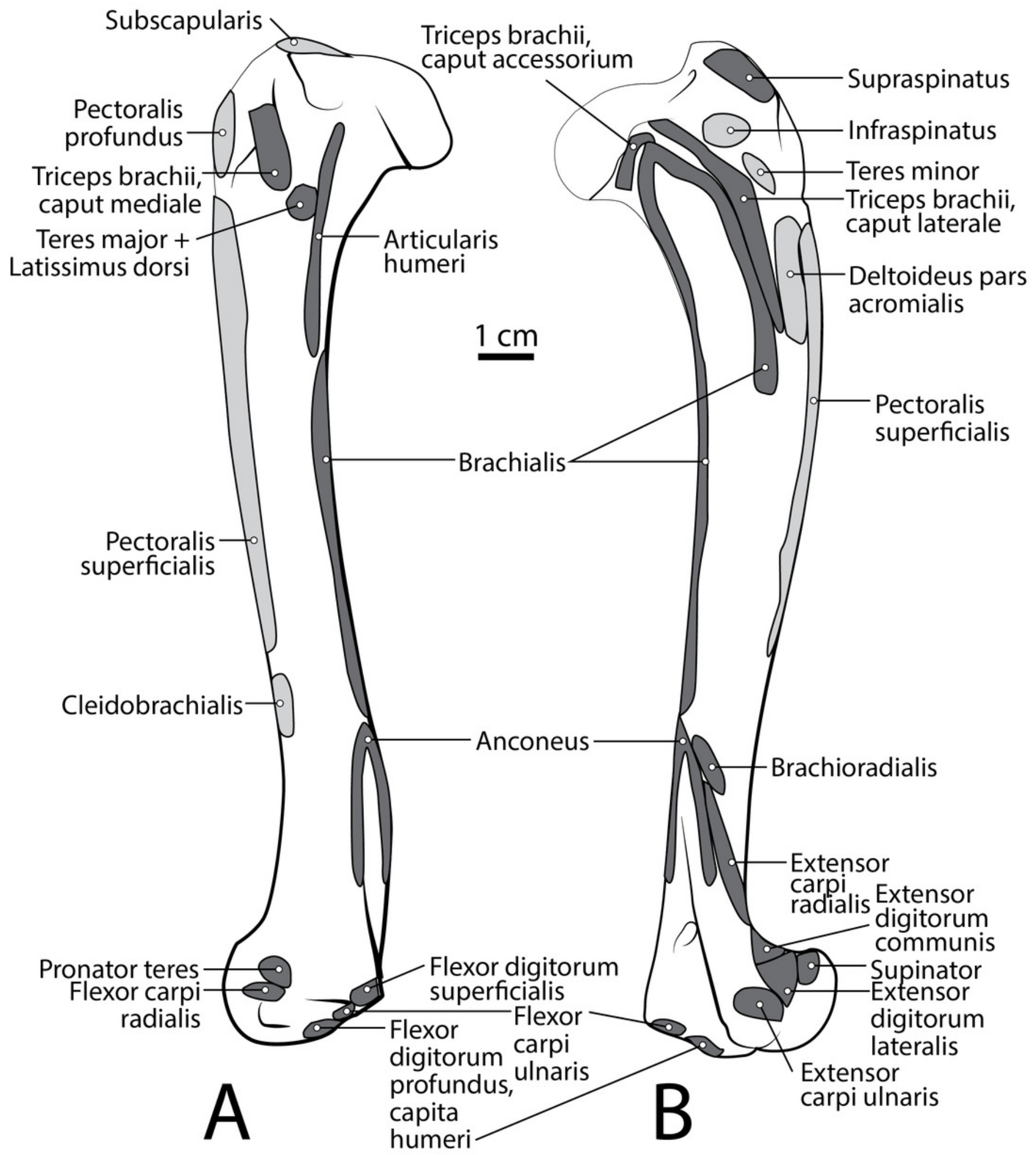




\section{Figure 6}

Lateral view of the superficial right antebrachium in L. pictus, including $\mathrm{mm}$. biceps brachii, brachialis, and anconeus.

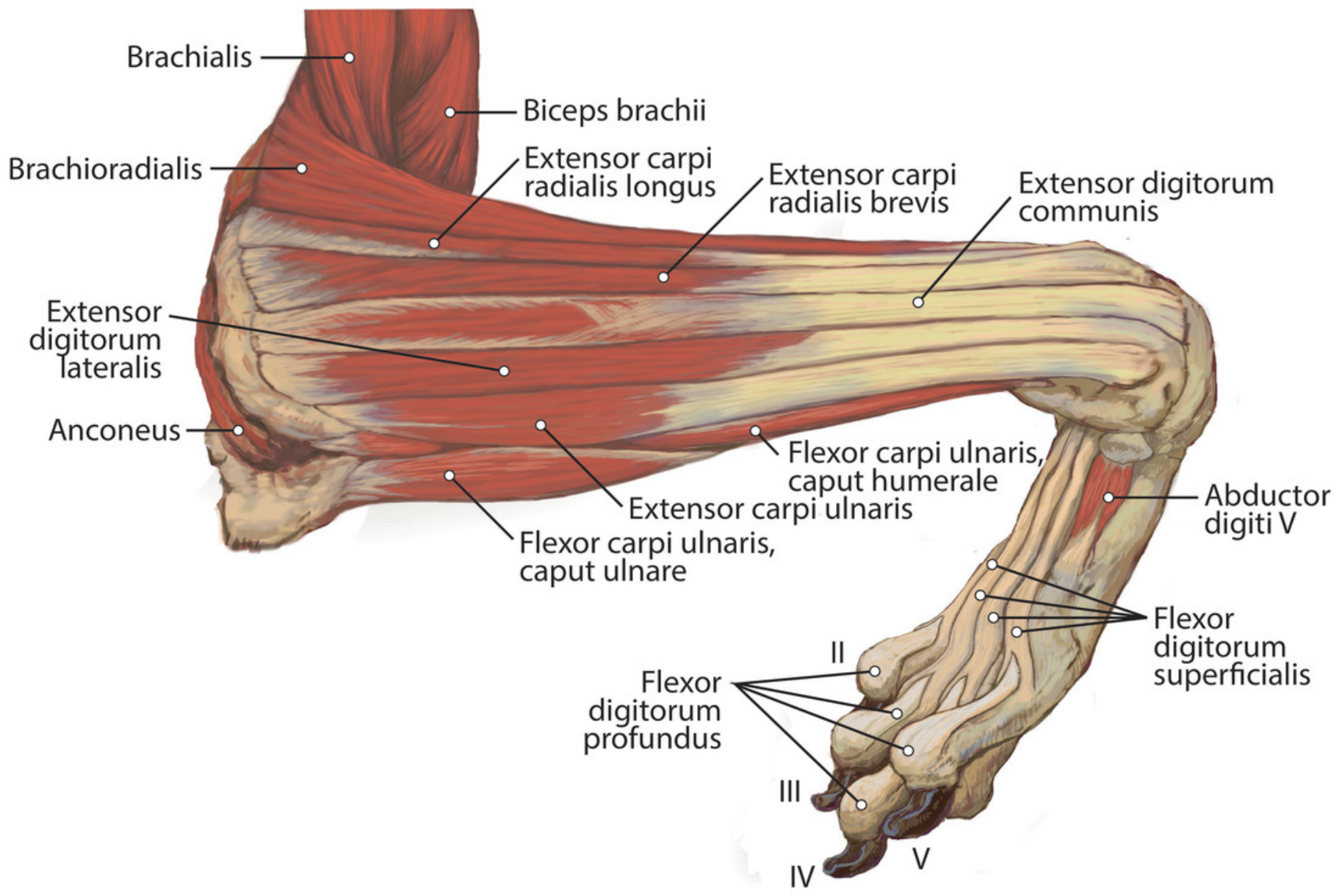




\section{Figure 7}

Lateral view of the deep right antebrachium in L. pictus.

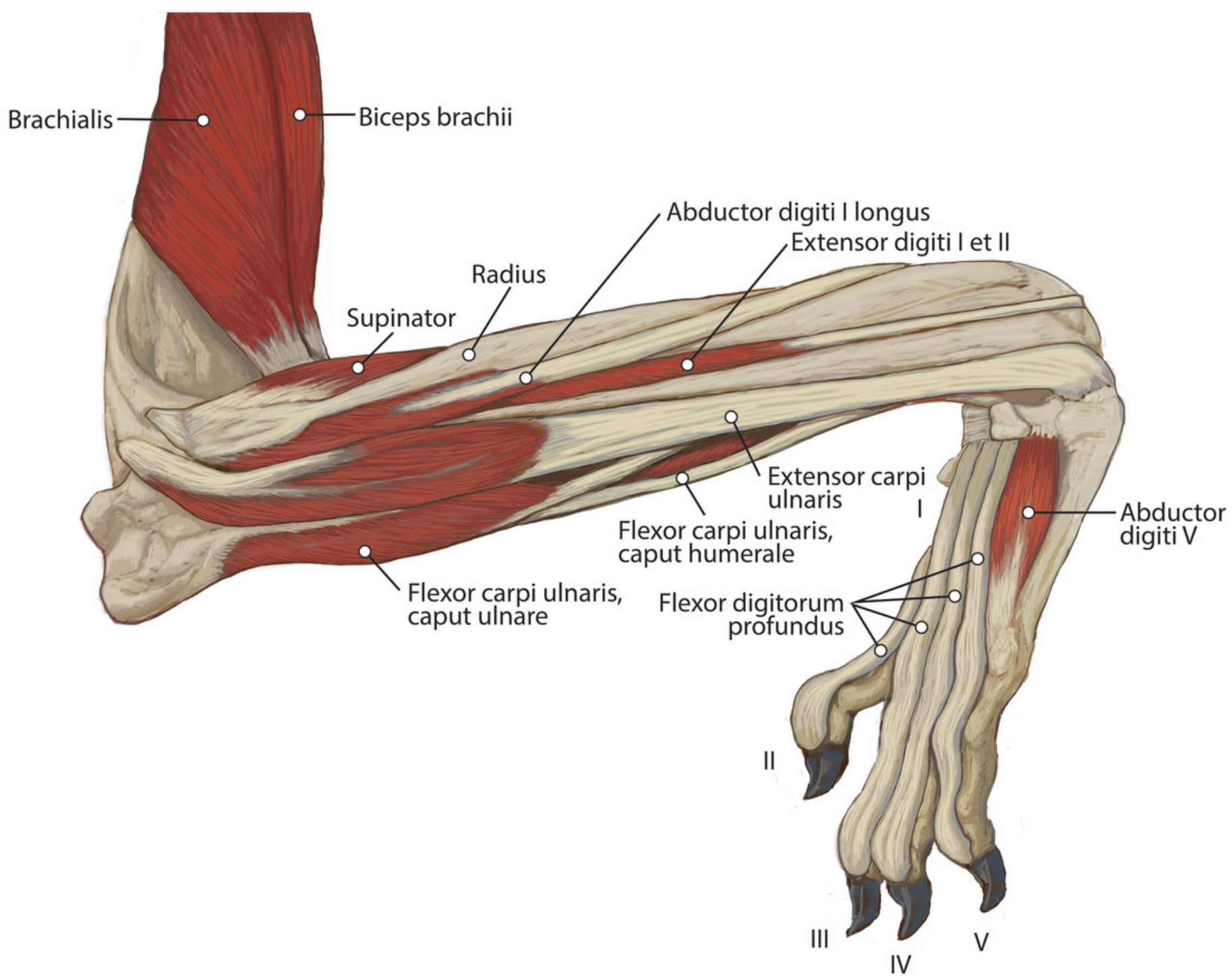


Figure 8

Medial view of the right antebrachium in L. pictus, including $\mathrm{mm}$. biceps brachii and brachioradialis.

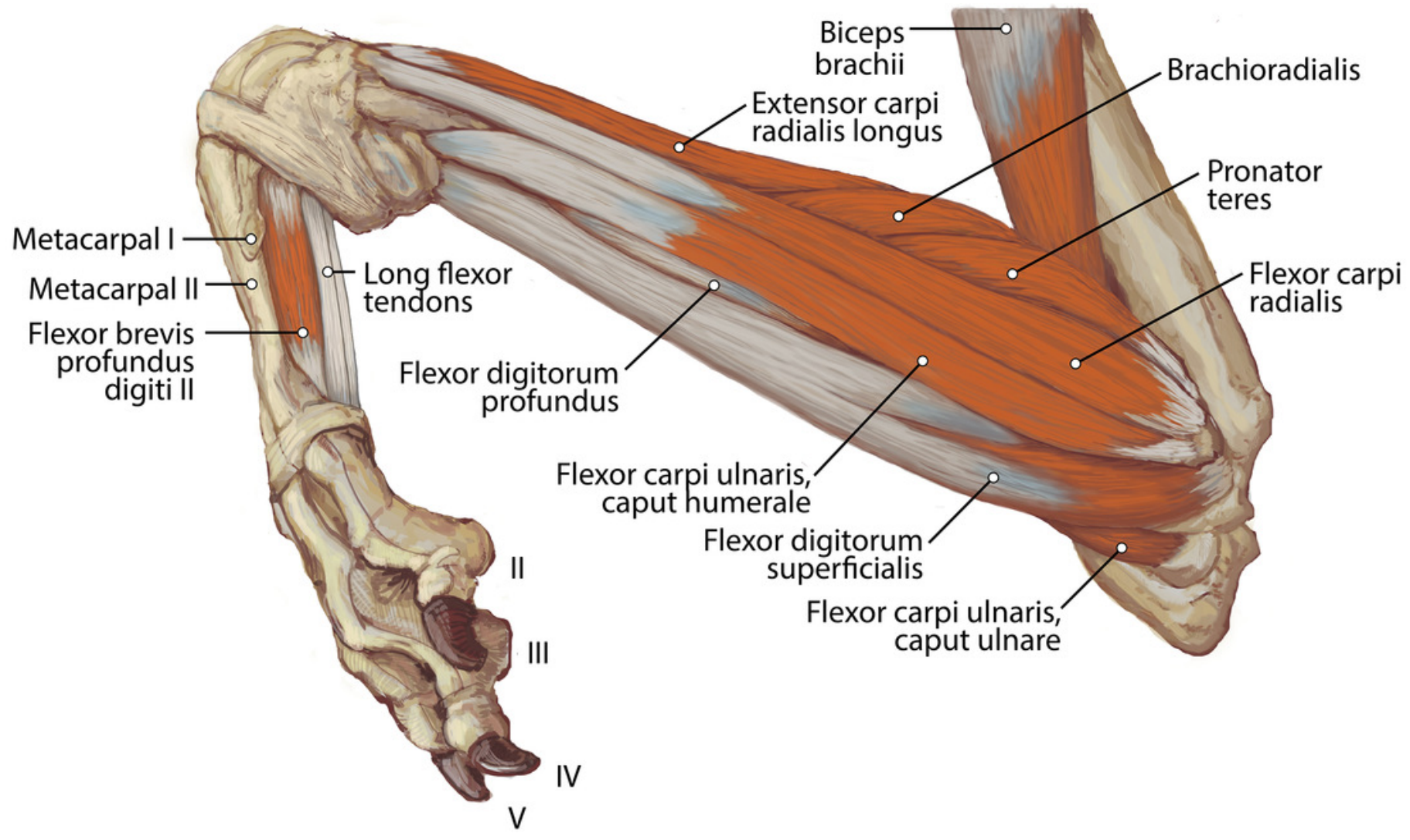


Figure 9

Ulna muscle maps for $L$. pictus (right side): (A) lateral view; (B) medial view. 
Triceps brachii: capita longum + magnum +
accessorium + laterale

\section{Anconeus}
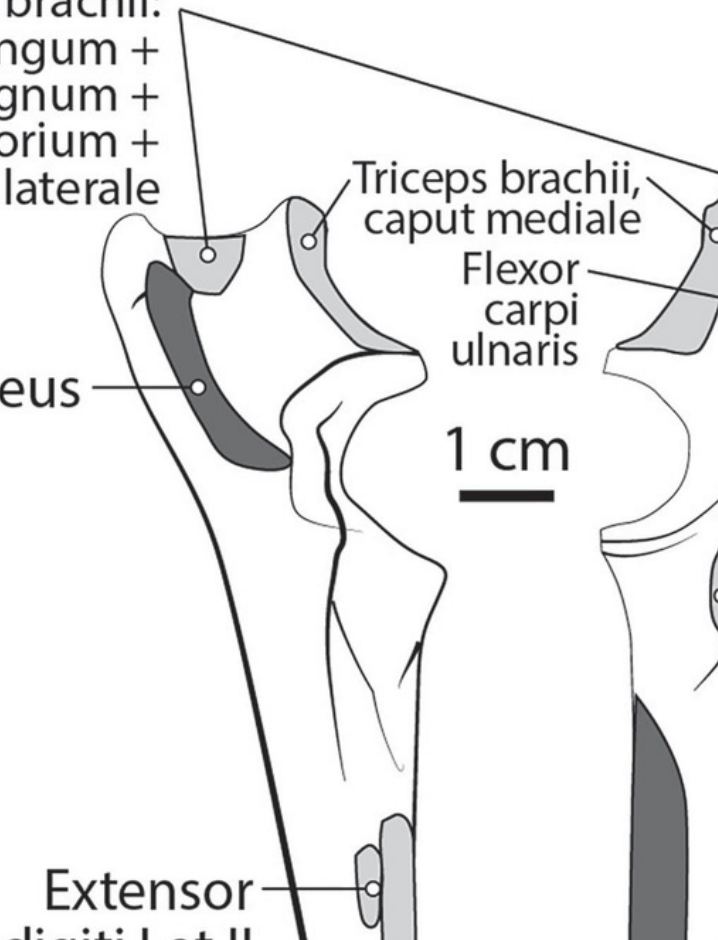
digiti I et II

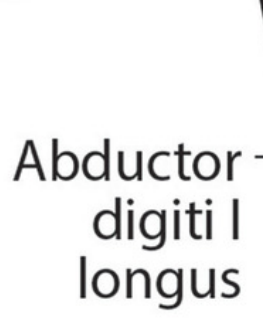

digiti I
longus 
Figure 10

Radius muscle maps for L. pictus (right side): (A) medial view; (B) lateral view. 


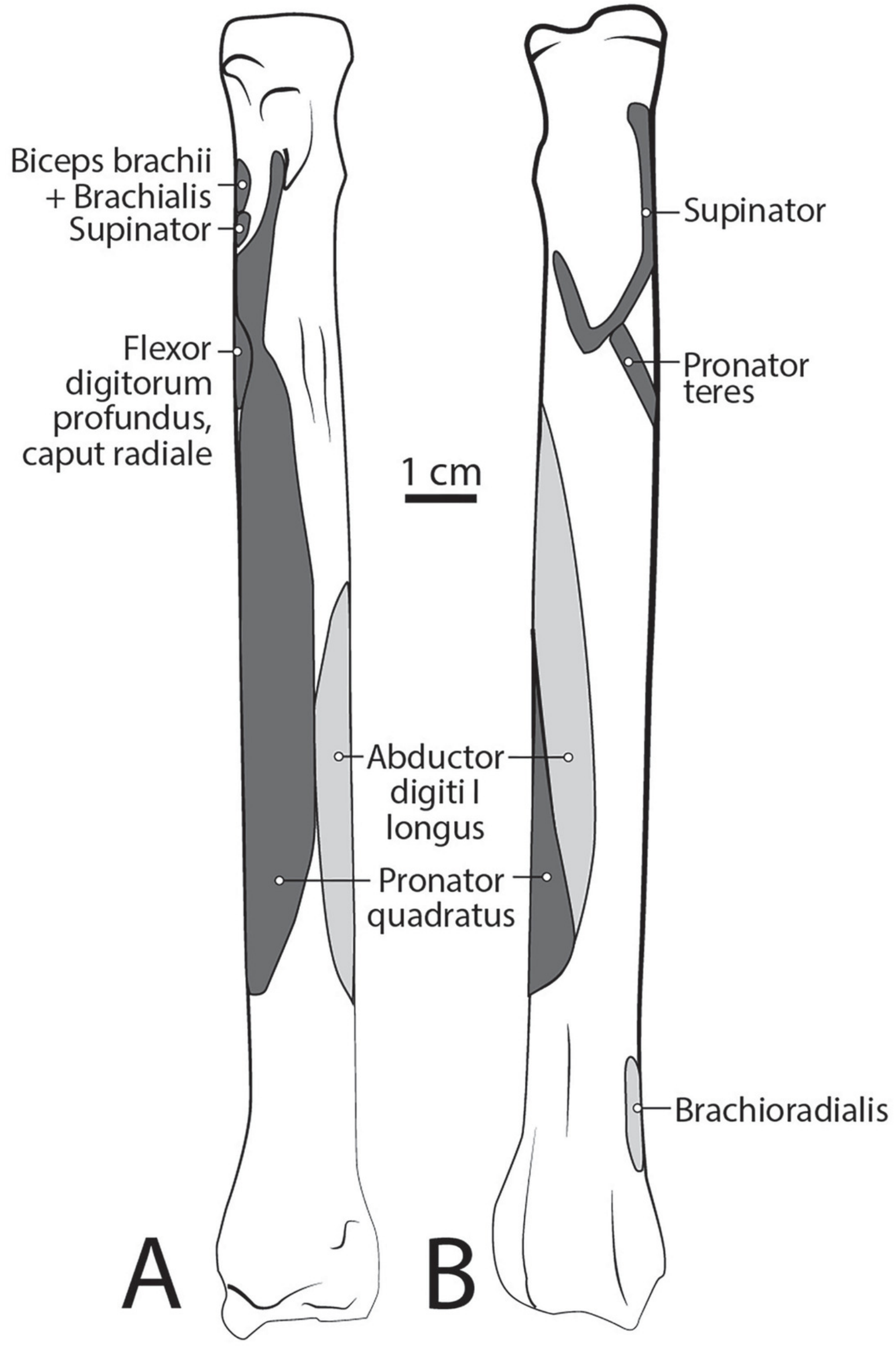


Figure 11

Dorsal manus muscle maps for L. pictus (right side). 


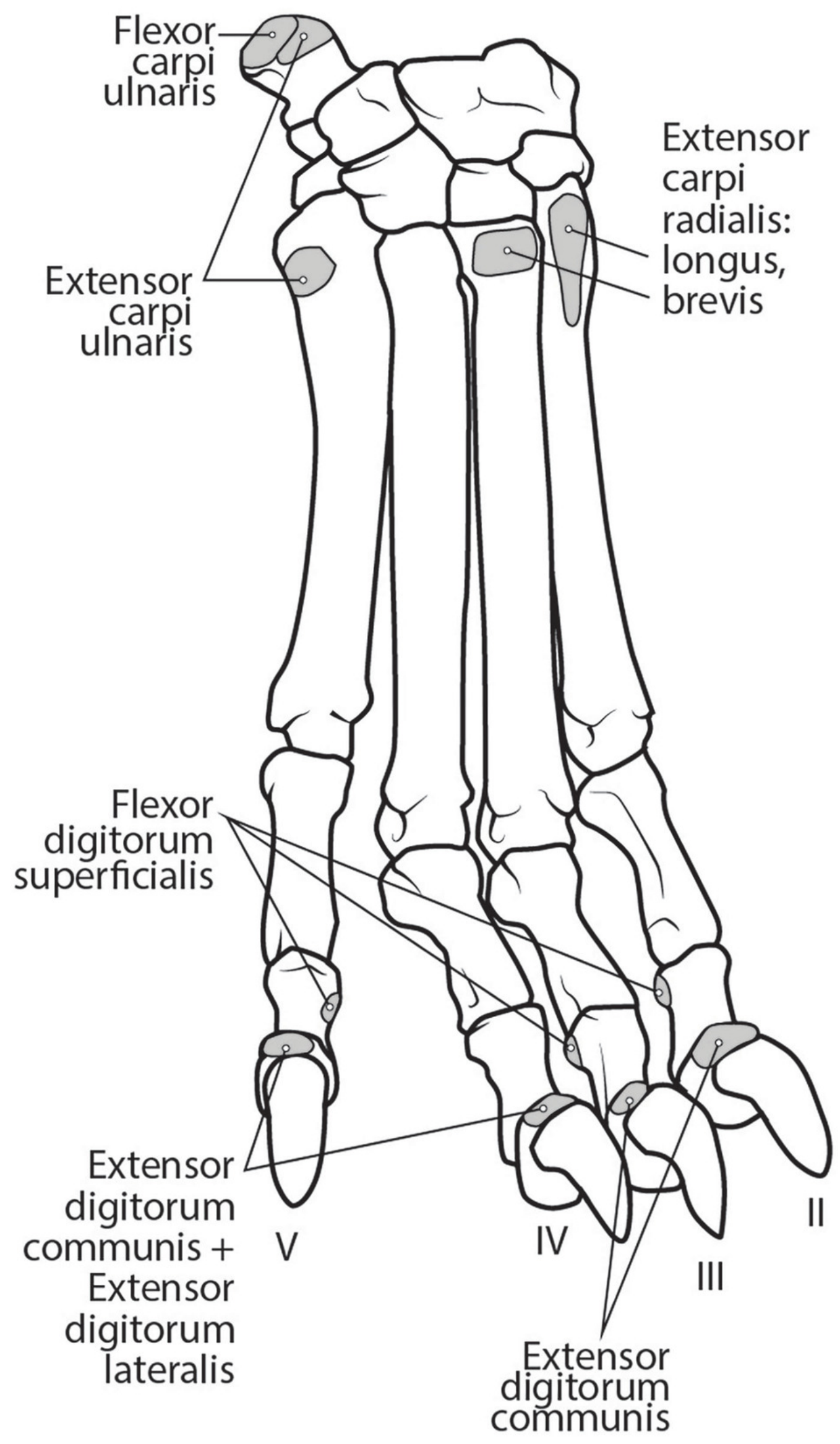


Figure 12

Palmar view of manus muscles in L. pictus (right side): (A) superficial view; (B) deep view. 


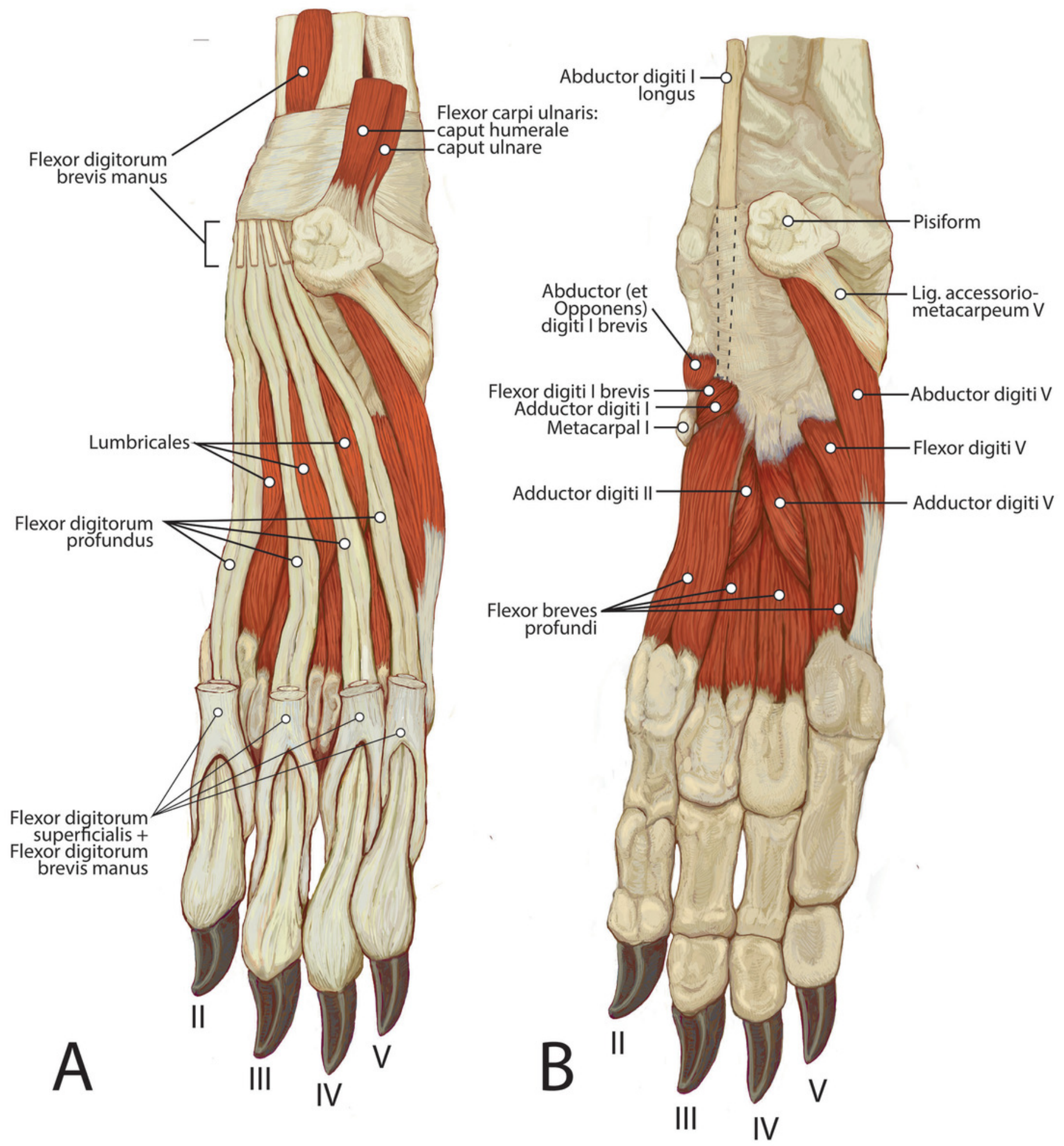




\section{Figure 13}

Insertions of mm. biceps brachii and brachialis: (A) photograph of Lycaon pictus; (B) illustration of L. pictus; (C) illustration of Canis familiaris.

Numbers indicate: $3=\mathrm{m}$. biceps brachii; $9=\mathrm{m}$. brachialis; $42=\mathrm{m}$. flexor digitorum superficialis; $43=\mathrm{m}$. flexor digitorum profundus; $44=\mathrm{m}$. flexor carpi radialis. Note that in $L$. pictus, the tendons of $\mathrm{mm}$. biceps brachii and brachialis fuse to insert together onto both the radius and ulna, while in $C$. familiaris the $m$. brachialis tendon travels through a split in the tendon of $\mathrm{m}$. biceps brachii to insert exclusively onto the ulna.

A

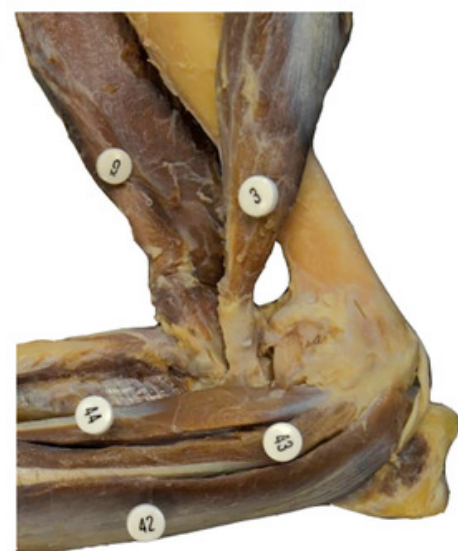

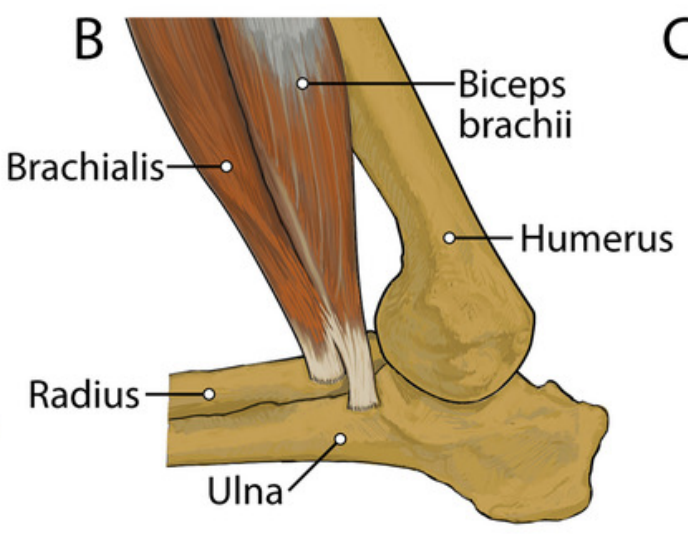

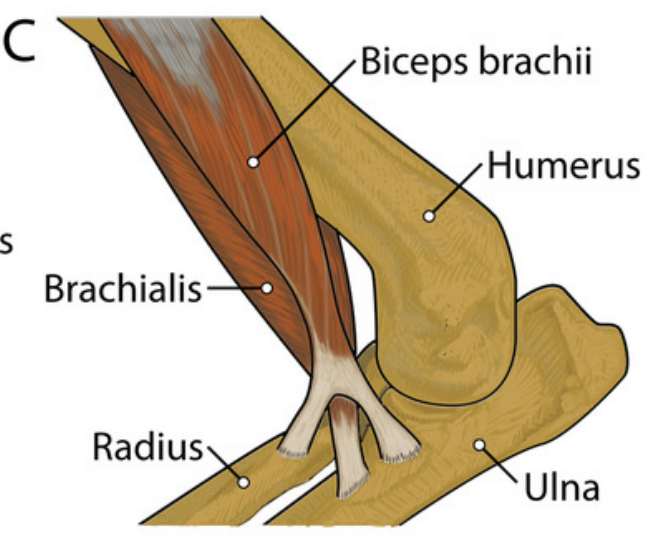

